\title{
Strength in numbers: preventing rereplication via multiple mechanisms in eukaryotic cells
}

\author{
Emily E. Arias ${ }^{1}$ and Johannes C. Walter ${ }^{2}$ \\ Department of Biological Chemistry and Molecular Pharmacology, Harvard Medical School, 240 Longwood Avenue, \\ Boston, Massachusetts 02115, USA
}

In eukaryotic cells, prereplication complexes (pre-RCs) are assembled on chromatin in the G1 phase, rendering origins of DNA replication competent to initiate DNA synthesis. When DNA replication commences in $S$ phase, pre-RCs are disassembled, and multiple initiations from the same origin do not occur because new rounds of pre-RC assembly are inhibited. In most experimental organisms, multiple mechanisms that prevent pre-RC assembly have now been identified, and rereplication within the same cell cycle can be induced through defined perturbations of these mechanisms. This review summarizes the diverse array of inhibitory pathways used by different organisms to prevent pre-RC assembly, and focuses on the challenge of understanding how in any one cell type, various mechanisms cooperate to strictly enforce once per cell cycle regulation of DNA replication.

The ability of eukaryotic cells to duplicate vast amounts of genetic information quickly and accurately before each cell division is an awe-inspiring product of evolution. To achieve rapid replication, cells use a parallel processing approach in which multiple replisomes copy DNA simultaneously. A dramatic example of this strategy occurs during the early cleavage divisions of the frog Xenopus laevis, in which DNA replication initiates from $\sim 300,000$ sites, called origins, which are spaced $\sim 10 \mathrm{~kb}$ apart (Blow 2001). As a result, 3 billion base pairs of DNA are duplicated within minutes. All eukaryotic organisms use a similar strategy, and the number of origins employed is generally correlated to the genome size and the length of the cell cycle. To ensure that DNA replication is not only fast, but accurate, it is essential that no segment of the chromosome be duplicated more than once. Indeed, reinitiation from even a single origin within the same cell cycle may cause genome instabil-

[Keywords: Cdt1; Cul4; DNA replication; MCM2-7; ORC; SCF]

${ }^{1}$ Present address: Laboratory of Chemistry and Cell Biology, Rockefeller University, 1230 York Avenue, New York, NY 10021.

${ }^{2}$ Corresponding author.

E-MAIL johannes_walter@hms.harvard.edu; FAX (617) 738-0516.

Article is online at http://www.genesdev.org/cgi/doi/10.1101/gad.1508907. ity. Thus, the ability of cells to restrict DNA replication to a single round per cell cycle is a fundamental requirement of cell proliferation and long-term survival.

The two-state model for cell cycle regulation of DNA replication

Early insights into the regulation of eukaryotic DNA replication came from cell fusion experiments (Rao and Johnson 1970), which showed that union of an S-phase cell with a G1 cell accelerates the rate at which the latter enters S phase. In contrast, G2 cells are refractory to this stimulation. These results suggested that the initiation of DNA synthesis requires a positive, diffusible S-phasepromoting activity, and that G1 but not G2-phase cells are competent to respond to this signal. Building on these observations and on their own experiments in Xenopus egg extracts, Blow and Laskey (1988) developed the "licensing" model, in which a licensing factor that is required for replication initiation binds to chromatin in G1. At the G1/S transition, the factor is inactivated, and it cannot be replenished until cells pass through mitosis. These ideas were extended by in vivo footprinting experiments in yeast that showed that origins of replication alternate between two distinct states (Diffley et al. 1994). In G1, all origins exhibit a "prereplicative" pattern. In contrast, from the moment of initiation until passage through mitosis, the origin resides in a "postreplicative" state. Concurrently, experiments by Nurse and colleagues (Broek et al. 1991; Hayles et al. 1994) showed that cyclin-dependent kinases (CDKs) play a dual role in regulating DNA replication, being required not only to trigger replication initiation but also to limit DNA replication to a single round per cell cycle. When CDK activity is inhibited in G2 phase, origins of replication revert to the prereplicative state and reinitiation occurs (Dahmann et al. 1995; Piatti et al. 1996). Finally, the identification of the origin recognition complex (ORC), Cdc6, Cdt1, and the minichromosome maintenance (MCM) complex as licensing activities and/or key components of prereplication complexes (pre-RCs) gave molecular definition to the replication factors whose activity is controlled during the cell cycle (for review, see Bell and Dutta 2002). 
These seminal experiments coalesced into an elegant model for the cell cycle regulation of DNA replication, the essence of which is that DNA replication occurs in two discrete steps, which are closely correlated with oscillations in CDK activity (see Fig. 1A; Diffley 1996). The first step occurs soon after M-CDK activity drops upon exit from mitosis, and it involves the assembly of a pre$\mathrm{RC}$ at each origin via the ordered binding of at least four factors, ORC, Cdc6, Cdt1, and MCM2-7. The process of pre-RC assembly is often referred to as "licensing." The second step, replication initiation, is triggered by the increase in S-phase CDK activity (S-CDK), which occurs at the G1/S transition. When replication initiates, the pre$\mathrm{RC}$ reverts to a post-replicative state due to loss of the MCM2-7 complex. Multiple initiations from the same origin do not occur because once cells pass through the G1/S transition, they cannot load new MCM2-7 complexes onto origins. In short, the cell cycle oscillates between two functional states. During the first state, which covers G1 phase and is characterized by low CDK activity, pre-RCs are assembled but cannot undergo initiation. In the second state, which spans S, G2, and M phases, high CDK activity allows replication to initiate, but it also prevents de novo pre-RC assembly. This separation of initiation into two distinct phases, only the first of which is blocked by CDK activity, and the disassembly of pre-RCs upon initiation, together ensure that no origin of DNA replication can initiate more than once per cell cycle. An important corollary to this model is that the inhibitory mechanisms, which prevent de novo MCM2-7 recruitment have no effect on the stability of existing pre-RCs. Thus, at origins that initiate DNA replication late in S phase, pre-RCs persist on chromatin for extended periods in an environment that is refractory to new pre-RC formation.

One important question that was left open by this model was whether CDK prevents rereplication by inhibiting the licensing reaction directly, or whether it functions indirectly, by specifying cell cycle position. As discussed in this review, detailed molecular mechanisms that prevent licensing have now been characterized in all major experimental systems. In yeast, this work has provided unequivocal evidence that CDKs directly inhibit origin licensing through direct phosphorylation of preRC components. In multicellular eukaryotes the evidence for direct CDK-mediated inhibition of pre-RC assembly is weaker, and, in contrast to yeast, the existence of CDK-independent mechanisms has been clearly established.

\section{Step one: licensing origins of replication via pre-RC formation}

All known mechanisms that restrict DNA replication to a single round per cell cycle inhibit the first phase of replication initiation, origin licensing (for review, see Bell and Dutta 2002; Blow and Dutta 2005). Licensing begins with DNA binding of the ORC, a six-subunit $\mathrm{AAA}^{+}$ATPase (Fig. 2). In budding and fission yeasts, ORC binds chromatin throughout the cell cycle, but in higher eukaryotes ORC phosphorylation during mitosis causes its transient release from chromatin (for review, see DePamphilis 2005). In Saccharomyces cerevisiae, ATP binding by ORC is required for the specific recognition of origin DNA sequences, and in multicellular eukaryotes, where ORC exhibits little or no sequence specificity, ATP binding is required for efficient interaction with any DNA sequence (for review, see Cvetic and Walter 2005). Chromatin-bound ORC recruits two additional proteins, Cdc6, another $\mathrm{AAA}^{+}$ATPase, and Cdt1, a coiled-coil domain protein. Together, ORC, Cdc6, and Cdt1 facilitate chromatin loading of the MCM2-7 com-

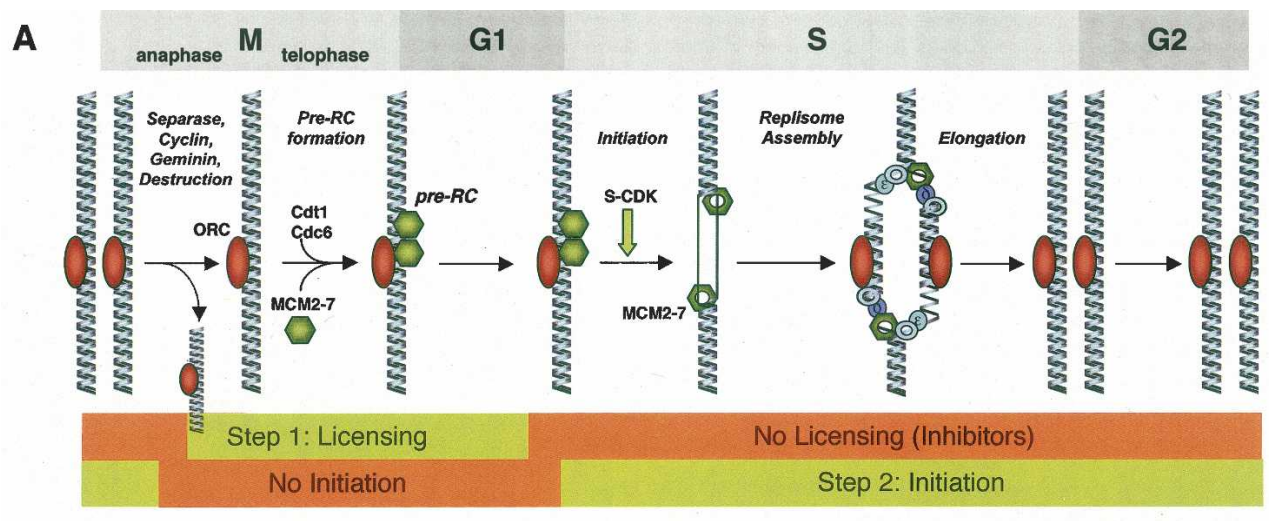

B

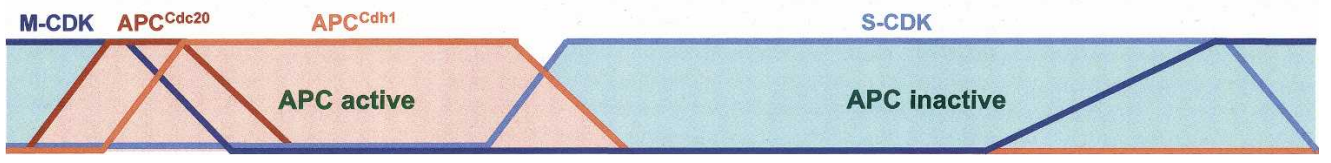

Figure 1. Two-step model for the cell cycle regulation of eukaryotic DNA replication. $(A)$ The events that occur at origins of DNA replication at different stages of the cell cycle are shown. The green bars indicate when in the cell cycle licensing and initiation, respectively, are allowed. (B) Oscillations in APC and CDK activity during the cell cycle are indicated. 


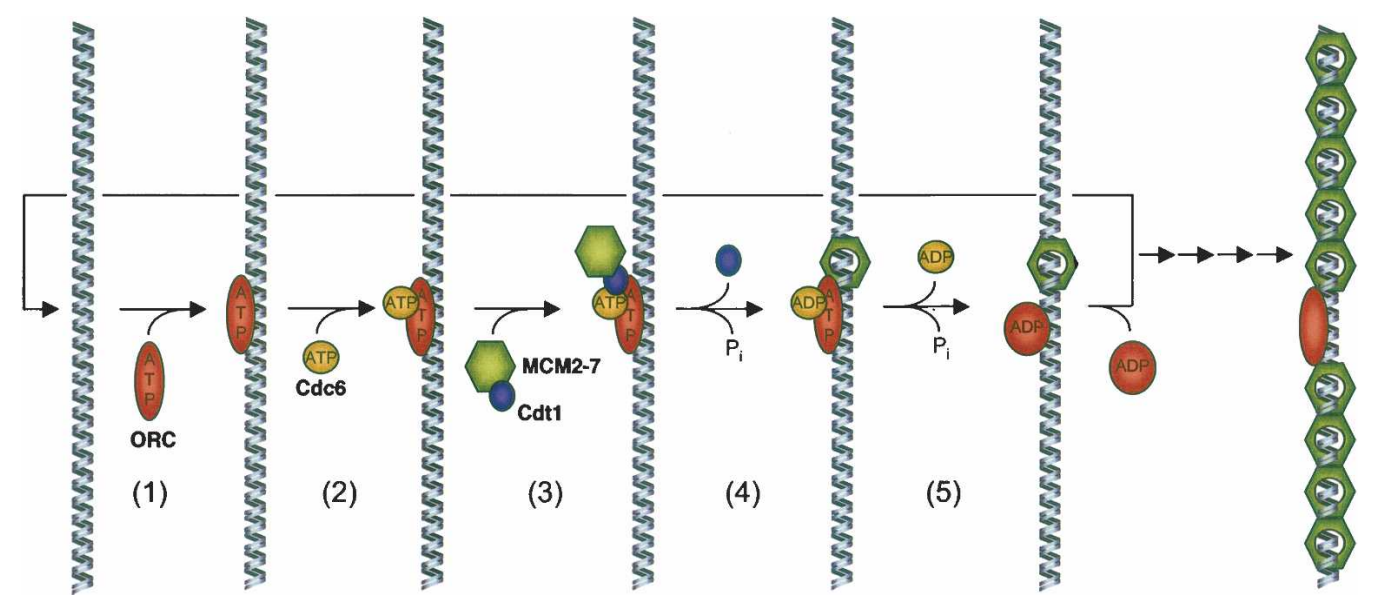

Figure 2. Model for the mechanism of pre-RC assembly in yeast. ORC:ATP binds to origin DNA (1) and recruits Cdc6:ATP (2). (3) ORC and Cde6 then recruit a complex of MCM2-7 and Cdt1. (4) Upon ATP hydrolysis by Cdc6, MCM2-7 binds tightly to DNA, possibly by encircling the duplex. (5) ORC hyrdrolyzes ATP. The resulting conformational change releases MCM2-7 and presumably leads to release of the ORC complex from DNA. The cycle begins anew when a new ORC:ATP complex binds to the origin. Repetition of these five steps leads to the recruitment of multiple MCM2-7 complexes to a single origin of DNA replication.

plex, which almost certainly functions as the replicative DNA helicase (see below). Recent experiments in licensing-competent yeast extracts suggest distinct functions for the ATPase activities of ORC and Cdc6 in MCM2-7 recruitment (Bowers et al. 2004; Randell et al. 2006). Thus, when ATP hydrolysis by Cdc6 is blocked, MCM2-7 binds origin DNA but remains loosely associated. In contrast, in the absence of ATP hydrolysis by ORC, MCM2-7 is loaded and associates tightly with the origin, but the number of MCM2-7 complexes that bind to each origin is reduced. Interestingly, $S$. cerevisiae Cdt1 forms a complex with MCM2-7 in solution, but Cdt1 is only stably bound to the origin when ATP hydrolysis by Cdc6 is blocked (Tanaka and Diffley 2002; Randell et al. 2006). Together, these observations support a model in which Cdc6 associates with ORC, after which MCM2-7 is escorted to the origin via Cdt1 (Fig. 2). ATP hydrolysis by Cdc6 causes a conformational change in MCM2-7, which induces tight MCM2-7 binding to DNA and displacement of Cdt1. Finally, ATP hydrolysis by ORC inaugurates a new round of MCM2-7 loading. This cycle appears to be repeated multiple times, yielding pre-RCs containing many MCM2-7 complexes (see below). Unlike yeast Cdt1, metazoan Cdt1 does not form a stable complex with MCM2-7, but direct binding of Cdt1 to MCM2-7 is nevertheless thought to be essential for pre-RC assembly (Yanagi et al. 2002; Cook et al. 2004; Ferenbach et al. 2005).

In the last decade, a compelling body of evidence has accumulated that suggests that the MCM2-7 complex is the replicative DNA helicase. First, like most other replicative DNA helicases, the MCM2-7 complex consists of six $\mathrm{AAA}^{+}$ATPase subunits (Mcm2-Mcm7), which assemble into a ring-shaped hexamer. Second, recombinant $\mathrm{Mcm} 4 / \mathrm{Mcm} 6 / \mathrm{Mcm} 7$ subcomplexes from numerous eukaryotic organisms exhibit ATPase-dependent helicase activity, although they are not highly processive (for review, see Takahashi et al. 2005). Third, MCM2-7 travels with and is required for movement of the replisome (Aparicio et al. 1997; Labib et al. 2000; Pacek and Walter 2004). Fourth, ATP hydrolysis-deficient mutants of MCM2-7 assemble into pre-RCs but are specifically blocked at the origin-unwinding step (Ying and Gautier 2005). Fifth, inhibition of MCM2-7 blocks DNA unwinding at the replication fork (Pacek and Walter 2004; Shechter et al. 2004). Finally, MCM2-7 localizes to the site of unwinding under conditions when the replicative DNA helicase is uncoupled from the rest of the replisome (Pacek et al. 2006).

Interestingly, recent evidence suggests that MCM2-7 may not unwind DNA on its own. MCM2-7 has been purified in a ternary complex with two other replication initiation factors, Cdc45 and GINS (Kubota et al. 2003; Masuda et al. 2003; Gambus et al. 2006; Moyer et al. 2006), and highly purified preparations of this complex exhibit helicase activity (Moyer et al. 2006). Importantly, Cdc45 and GINS are associated with replication forks and are required for their progression (Aparicio et al. 1997; Tercero et al. 2000; Takayama et al. 2003; Pacek and Walter 2004; Pacek et al. 2006). Moreover, inhibition of Cdc45 blocks DNA unwinding at the replication fork in Xenopus egg extracts, and both Cdc45 and GINS associate with the uncoupled DNA helicase (Pacek and Walter 2004; Pacek et al. 2006). Because Cdc45 and GINS lack ATPase motifs, the data collectively suggest that MCM2-7 is the engine that stimulates DNA unwinding, while Cdc45 and GINS play auxiliary functions.

Considering that MCM2-7 likely functions as the replicative DNA helicase, it is puzzling that in most organisms, between five and 40 MCM2-7 complexes bind to each origin of DNA replication (Fig. 2; Randell et al. 2006; for review see Takahashi et al. 2005). In Xenopus egg extracts, these multiple MCM2-7 complexes are widely distributed on DNA, and they all appear to be functional (Edwards et al. 2002; Harvey and Newport 2003; Woodward et al. 2006). However, only a small sub- 
set of the chromatin-bound complexes is normally required to support efficient DNA replication in this system (Mahbubani et al. 1997; Edwards et al. 2002; Woodward et al. 2006). In yeast, mutations in ORC that limit the number of MCM2-7 complexes loaded onto each origin of replication are lethal (Randell et al. 2006), but the reason underlying lethality is unknown. Presently, it is unclear why so many MCM2-7 complexes are loaded onto origins, although several models have been proposed that suggest that the "latent" MCM2-7 complexes are activated during replicative crises (Edwards et al. 2002; Hyrien et al. 2003; Woodward et al. 2006). Whatever their function, all the MCM2-7 complexes associated with chromatin must be removed during the first round of DNA replication to prevent reinitiation. Most likely, passage of the DNA replication fork displaces latent MCM2-7 complexes (Brewer and Fangman 1993; Santocanale et al. 1999).

The dynamics of pre-RCs are highly relevant for the cell cycle regulation of DNA replication. MCM2-7 complexes bind very stably to DNA, being resistant to extraction by high salt (Donovan et al. 1997; Rowles et al. 1999; Edwards et al. 2002; Bowers et al. 2004), consistent with the observation that MCM2-7 complexes persist at origins for extended periods of the cell cycle, especially at late origins. The molecular basis for MCM2-7's tight grip on DNA is not understood, although it has been proposed that MCM2-7 may encircle double-stranded DNA within pre-RCs (Mendez and Stillman 2003; Takahashi et al. 2005). This idea is based in part on the apparent similarity between pre-RC assembly and the deposition of polymerase processivity factors onto DNA by clamp loaders (Perkins and Diffley 1998; Randell et al. 2006). Importantly, after MCM2-7 is loaded, ORC, Cdc6, and Cdt1 are no longer required for initiation of DNA replication, indicating that their primary function in DNA replication is to deliver MCM2-7 to origins (Muzi Falconi et al. 1996; Hua and Newport 1998; Duncker et al. 1999; Rowles et al. 1999; Maiorano et al. 2000; Shimada et al. 2002). This feature of pre-RCs is crucial, because it means that ORC, Cdc6, and Cdt1 can be inactivated at the G1/S transition to prevent de novo pre-RC assembly without affecting subsequent initiation. Interestingly, it appears that binding of the MCM2-7 complex to origins of replication stimulates the dissociation of ORC, Cdc6, and Cdt1 (Rowles and Blow 1997; Harvey and Newport 2003; Randell et al. 2006). Dissociation from pre-RCs should liberate these factors for assembly of new pre-RCs elsewhere, while perhaps also rendering them more accessible for inactivation by proteolysis and other mechanisms when cells enter $S$ phase (see below).

\section{Step two: initiation of DNA replication and origin inactivation}

Origins that are licensed during the G1 phase do not initiate DNA synthesis until they are acted on by a plethora of other initiation factors in S phase (for recent reviews, see Bell and Dutta 2002; Takeda and Dutta
2005; Walter and Araki 2006). The key event in the initiation of DNA replication is thought to be activation of MCM2-7 helicase activity, which requires assembly of the Cdc45-GINS-MCM2-7 complex. Briefly, two protein kinases, CDK and DDK (Dbf4 and Drf1-dependent kinase) cooperate with many other factors, including Mcm10 and Dpb11, to deposit Cdc45 and GINS onto the MCM2-7 complex (Sld2 and Sld3, two proteins implicated in this process in yeast, remain to be clearly identified in metazoans). Recent evidence supports the longstanding idea that DDK functions by directly phosphorylating the MCM2-7 complex, an event believed to facilitate its interaction with Cdc45 (Masai et al. 2006; Sheu and Stillman 2006; Tsuji et al. 2006). While two CDK substrates, Sld2 and Sld3, have been identified in yeast (Masumoto et al. 2002; Tanaka et al. 2007; Zegerman and Diffley 2007), the targets of this protein kinase are still unknown in metazoans. Once the origin is unwound, DNA polymerase $\alpha /$ primase is recruited, synthesizing an 10 nucleotide RNA primer, which it further extends with $\sim 30$ deoxynucleotides. The RNA-DNA primer is recognized by replication factor $\mathrm{C}$ (RFC), which displaces DNA polymerase $\alpha /$ primase and in turn recruits PCNA, a ring-shaped trimer that encircles DNA and functions as the processivity factor for DNA polymerase $\delta$ (Maga and Hubscher 2003).

The two-step, cell cycle regulation of DNA replication can now be described from the perspective of the replicative DNA helicase. In the G1 phase, origins of DNA replication are rendered competent when the core of the helicase, the MCM2-7 complex, is assembled into preRCs. In S phase, helicase assembly is completed with the recruitment of Cdc45 and GINS. During initiation, the pre-RC is dismantled when the helicase moves away from the origin. Critically, new MCM2-7 complexes cannot be recruited once cells enter S phase, so helicase reassembly, which would be required for reinitiation, is not possible. In contrast, the subsequent steps, Cdc45 and GINS recruitment, are promoted in S phase. Indeed, transient destruction of MCM2-7 in mid-S phase causes permanent cell cycle arrest, whereas after transient elimination of Cdc45, DNA replication resumes (Labib et al. 2000; Tercero et al. 2000). By targeting the replicative DNA helicase, cells block rereplication at the earliest enzymatic step of chromosome duplication, thereby minimizing the possibility of genomic instability.

\section{Anaphase-promoting complex (APC): the master regulator of licensing}

The cell cycle regulation of DNA replication is inextricably connected to the cell cycle engine, whose major feature is the periodic oscillation of CDK activity (Fig. 1B; for review, see Morgan 2007). CDKs consist of a catalytic subunit that is activated upon binding to a cyclin subunit, which also confers substrate specificity. Cyclins that control cell proliferation can be grouped into four categories: the G1 cyclins, the G1/S cyclins, the S-phase cyclins, and the M-phase cyclins. With few ex- 
ceptions, only the S- and M-phase CDKs inhibit pre-RC formation, so it is important to consider how their abundance is regulated. The exit from mitosis, which is marked by destruction of M-CDK activity, is stimulated by a multisubunit E3 ubiquitin ligase called the APC. M-CDKs promote their own destruction by phosphorylating a version of the APC that contains the activator protein $\mathrm{Cdc} 20\left(\mathrm{APC}^{\mathrm{Cdc} 20}\right)$. $\mathrm{APC}^{\mathrm{Cdc} 20}$ then targets Cyclins A and B for destruction. Importantly, most eukaryotic cells also express, APC ${ }^{\text {Cdh1 } 1}$, whose activator subunit Cdh1 is inhibited by M-CDK activity. Thus, when Mphase cyclins are destroyed, and APC ${ }^{\mathrm{Cdc} 20}$ becomes inactive, $\mathrm{APC}^{\mathrm{Cdh} 1}$ steps in. Like $\mathrm{APC}^{\mathrm{Cdc} 20}, \mathrm{APC}^{\mathrm{Cdh} 1}$ destroys $\mathrm{M}$ - and S-phase-specific cyclins, and stabilizes CDK inhibitors (CKIs). APC ${ }^{\mathrm{Cdh} 1}$ thereby perpetuates a G1 state that is characterized by low S- and M-CDK activity. The G1 phase ends when growth signals activate expression of G1/S cyclins. G1/S-CDKs, which are not substrates of APC ${ }^{\mathrm{Cdh} 1}$, phosphorylate and switch off AP$\mathrm{C}^{\mathrm{Cdh} 1}$. $\mathrm{APC}^{\mathrm{Cdh} 1}$ activity is also blocked in $\mathrm{S}$ and $\mathrm{G} 2$ phase by Emil. Subsequently, S- and M-phase cyclins can reaccumulate and CKIs are destroyed. In yeast, activation of APC at the end of mitosis sets the stage for origin licensing by establishing a window of low S/MCDK activity. In higher eukaryotes, the APC additionally targets the licensing inhibitor Geminin (see below). In summary, the APC is a master regulator whose activity determines whether cells are in a state that is permissive or restrictive for pre-RC formation.

\section{Rereplication, failed mitosis, endoreduplication, and gene amplification}

The ploidy of eukaryotic cells can change for a variety of reasons. First, during rereplication, replication origins initiate DNA synthesis more than once but there is no coordination between reinitiation events, and thus, the resulting increase in ploidy is usually partial. Second, if mitosis fails due to a defect in cytokinesis, cyclins are still destroyed by the APC, allowing pre-RC reassembly and progression into a new cell cycle. Mitotic failure causes a doubling of DNA content. Rereplication and mitotic failure are generally not programmed events, but rather result spontaneously from defects in the cell cycle machinery. Third, cells can undergo endoreduplication, which usually involves consecutive and complete S phases that are not separated by mitosis. Endocycles occur in many metazoans during normal development. Fourth, during gene amplification, specific segments of the chromosome undergo repeated initiation events, leading to increased copy number of particular loci. We collectively refer to these four phenomena as "overreplication." This review focuses primarily on the mechanisms that prevent rereplication.

\section{Redundancy and the regulation of origin firing}

It is generally assumed (but not proven) that reinitiation from even a single origin of DNA replication is undesir- able and possibly fatal. Considering that some eukaryotic cells initiate DNA replication at up to 300,000 sites during a single $\mathrm{S}$ phase, it follows that, in some cases, cells must reduce the incidence of origin refiring to $<0.0003 \%$. This requirement for virtually absolute repression of rereplication is probably why cells have developed multiple mechanisms to inhibit pre-RC assembly. The presence of multiple inhibitory mechanisms raises conceptual questions concerning redundancy that are intertwined with the details of experimental methods. Thus, if at least two separate mechanisms must be disrupted to detect rereplication in a particular system, and the limit of detection is $1 \%$ of the genome rereplicated, then it follows that each individual mechanism is by itself $>99 \%$ efficient. When acting together, these two mechanisms would achieve at least $99.99 \%$ repression. In this scenario, the mechanisms are overlapping, and they should not be considered functionally redundant unless each alone is sufficient to maintain genome stability over many generations. In some instances, inhibitory mechanisms have been characterized that are not essential for viability. Such mechanisms are considered dispensable. As discussed below, cells probably achieve the desired level of origin repression by employing multiple overlapping inhibitory mechanisms whose combined, multiplicative effect is adequate to support viability.

\section{Strategies to prevent rereplication in different eukaryotes}

Using defined manipulations, rereplication can now be induced in most major systems used to study eukaryotic DNA replication. As described in the sections below, these experiments indicate that all eukaryotes employ multiple mechanisms to prevent pre-RC formation, but the number, nature, and interplay of these mechanisms varies substantially between organisms.

\section{S. cerevisiae}

Budding yeast initiates DNA replication at some 400 origins of DNA replication in every $\mathrm{S}$ phase. This organism is unique in that every known inhibitory mechanism is dependent on CDK activity (see Fig. 3). These mechanisms target each of the pre-RC components, sometimes in multiple ways. Cdc6 is inhibited at three levels. First, phosphorylation of Cdc6 marks it for ubiquitylation by the E3 ligase $\mathrm{SCF}^{\mathrm{Cdc} 4}$, leading to proteasome-mediated destruction (Drury et al. 1997). Second, CDK inhibits Cdc6 transcription by blocking the nuclear import of the transcription factor, Swi5 (Moll et al. 1991). Finally, phosphorylation of Cdc6 at $\mathrm{N}$-terminal CDK sites induces stable association with the mitotic CDK, Clb2Cdc28, which blocks the licensing activity of Cdc6 (Mimura et al. 2004). The MCM2-7 complex is exported from the nucleus under the control of CDK phosphorylation (Labib et al. 1999; Nguyen et al. 2000; Liku et al. 2005), which also localizes Cdt1 to the cytoplasm during 
Figure 3. Species-specific pathways that prevent rereplication. The top of the figure shows the different stages of the eukaryotic cell cycle. For each species, each regulatory mechanism and the time in the cell cycle when it is active is represented by a horizontal bar. (Gray) Uncomfirmed pathways; (green) pathways that are directly regulated by CDK activity; (blue) PCNAdependent Cdt1 proteolysis pathways; (yellow) Geminin.

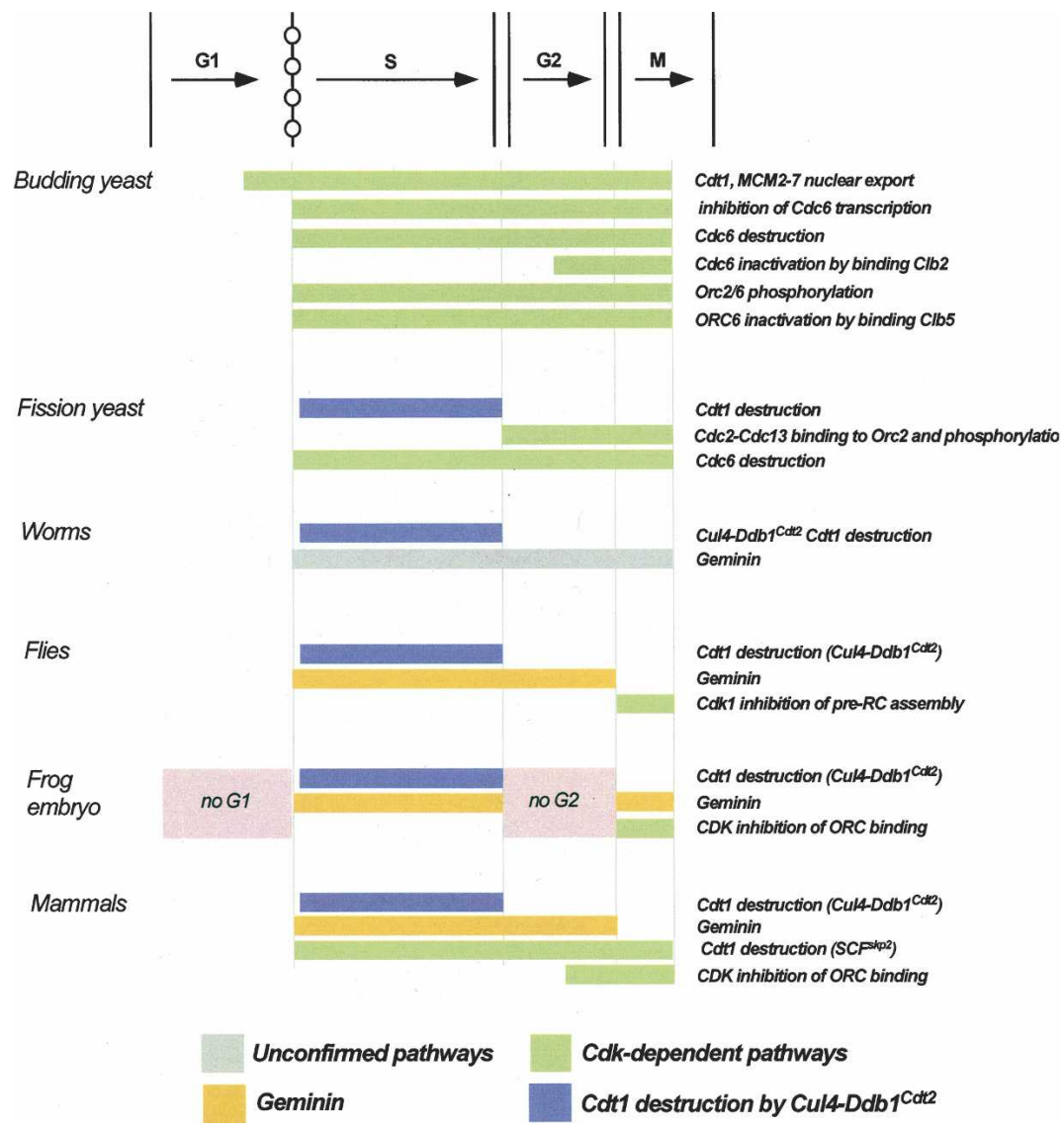

cant rereplication (see Table 1, rows 1-8; Nguyen et al. 2001; Vas et al. 2001). In other words, any single mechanism was sufficient to block detectable rereplication. The paper concluded that rereplication is prevented by overlapping mechanisms, but has often also been interpreted as evidence that three redundant mechanisms block rereplication. In a later study, a mutation in the RXL motif in Orc6 was combined with the other three mutations, and was found to further sensitize cells to rereplication, supporting an important role for Clb5 binding to Orc6 (Table 1, rows 10 and 12; Wilmes et al. 2004).

More recently, microarray comparative genomic hybridization (CGH) has been used to measure rereplication in these strains (Green et al. 2006; Tanny et al. 2006). Using this more sensitive assay, deregulation of only two pre-RC components (ORC and Cdc6) was now sufficient to cause rereplication on most chromosomes (Table 1, row 14). Thus, the remaining inhibitory mechanisms, MCM2-7/Cdt1 export and the binding of Clb5 to Orc6, are in fact not sufficient to prevent rereplication. Analogously, when MCM2-7/Cdt1 and Cdc6 were deregulated, rereplication occurred, but it was only detectable at a single origin of replication (Table 1, row 15). While this latter result shows that the combined mechanisms targeting ORC are quite potent in preventing the vast majority of rereplication, they are not sufficient for complete inhibition. The $\mathrm{CGH}$ data amend the earlier FACS results to show that no single inhibitory mecha- 
Table 1. Conditions that induce rereplication in S. cerevisiae

\begin{tabular}{|c|c|c|c|c|c|c|c|c|c|c|}
\hline & Re-replicatio & Assay & $\begin{array}{c}\text { Cdc6 } \\
\text { transcription }\end{array}$ & $\begin{array}{c}\text { Cdc6 } \\
\text { proteolysis }\end{array}$ & $\begin{array}{c}\text { Cdc6 } \\
\text { CDK binding }\end{array}$ & $\begin{array}{c}\text { MCM2-7/Cdt1 } \\
\text { Nuclear exprt }\end{array}$ & $\begin{array}{c}\text { ORC2 } \\
\text { P-ylation }\end{array}$ & $\begin{array}{c}\text { ORC6 } \\
\text { P-ylation }\end{array}$ & $\begin{array}{c}\text { ORC6 } \\
\text { CDK binding }\end{array}$ & \multirow{2}{*}{$\begin{array}{c}\text { Reference } \\
\text { Nguyen et al., } 2001\end{array}$} \\
\hline 1 & $0 \%$ & FACS & & & & & & & & \\
\hline 2 & $0 \%$ & FACS & & $\triangle N T-C d c 6$ & & & & & & $"$ \\
\hline 3 & $0 \%$ & FACS & & & & Mcm7-NLS & & & & $"$ \\
\hline 4 & $0 \%$ & FACS & & & & & Orc2-4A & Orc6--6A & & $"$ \\
\hline 5 & $0 \%$ & FACS & & & & & & & & $"$ \\
\hline 6 & $0 \%$ & FACS & & & & & & & & $"$ \\
\hline 7 & $0 \%$ & FACS & & & & & & & & $"$ \\
\hline 8 & $-50 \%$ & FACS & & & & & & & & $"$ \\
\hline 9 & $0 \%$ & FACS & & & & & & & & Wilmes et al., 2004 \\
\hline 10 & $\sim 30 \%$ & FACS & & & & & & & Orc6- $\triangle R X L$ & $"$ \\
\hline 11 & $0 \%$ & FACS & & & & & & & & $"$ \\
\hline 12 & $\sim 100 \%$ & FACS & & & & & & & & $"$ \\
\hline 13 & $0 \%$ & $\mathrm{CGH}$ & & & & & & & & Green et al., 2006 \\
\hline 14 & $\sim 10 \%$ & $\mathrm{CGH}$ & & & & & & & & $"$ \\
\hline 15 & $\sim 1 \%$ & $\mathrm{CGH}$ & & & & & & & & $"$ \\
\hline & & $\begin{array}{l}\text { black fie } \\
\text { green fig } \\
\text { red field }\end{array}$ & $\begin{array}{l}\text {, inactivate } \\
\text { active mech } \\
\text { active me }\end{array}$ & $\begin{array}{l}\text { lechanisms } \\
\text { anisms whic } \\
\text { sms which a }\end{array}$ & $\begin{array}{l}\text { ogether are } \\
\text { unable to }\end{array}$ & $\begin{array}{l}\text { Ifficient to preve } \\
\text { vent detectable }\end{array}$ & tetectable & -replication & & \\
\hline
\end{tabular}

nism is by itself sufficient to block rereplication, suggesting that the control of rereplication is not redundant (Green et al. 2006).

The most difficult remaining question is what contribution any individual inhibitory mechanism makes in the context of the other mechanisms. Can some mechanisms be eliminated without any consequences to the cell? Although the CGH assay detects no rereplication in cells in which only the ORC complex is deregulated (Table 1, column 13), this assay is still not very sensitive, since a positive result requires rereplication at the same locus in a significant percentage of cells. Moreover, although these cells show normal viability, standard assays cannot detect small numbers of dying cells. Thus, only when rereplication is detectable in individual cells will it become possible to address this issue. If elimination of individual inhibitory mechanisms has detectable effects in single-cell assays, it will clearly demonstrate that each inhibitory mechanism makes measurable contributions toward the prevention of rereplication, even when many other mechanisms are operative. Such a scenario would explain how multiple inhibitory mechanisms are maintained during evolution.

\section{Insulating licensing and initiation in S. cerevisiae}

With respect to regulating DNA replication, the most challenging periods of the cell cycle occur at the transition points between low and high CDK activity, when origin firing and pre-RC formation could potentially overlap (for review, see Diffley 2004). Thus, at the M/G1 transition, when CDK activity drops, it is crucial to insure that conditions that allow origin firing decline before pre-RCs are allowed to reassemble (Fig. 1A). This "insulation" is achieved in yeast through a temporally ordered cascade of protein degradation. At the metaphase-to-anaphase transition, $\mathrm{APC}^{\mathrm{Cdc} 20}$ ubiquitylates Clb5 and presumably Dbf4, eliminating the ability of cells to trigger replication initiation (Oshiro et al. 1999; Shirayama et al. 1999). Under these conditions, Clb2Cdc28, which is poor at stimulating initiation, is still present and prevents pre-RC formation (Donaldson 2000). Subsequently, APC ${ }^{\mathrm{Cdh} 1}$ triggers Clb2 destruction, allowing pre-RC formation. Thus, initiation becomes unfavorable before pre-RC assembly begins. Conversely, at the G1/S transition, it is crucial that the period of origin licensing ends before CDK activity rises, lest some origins initiate twice. To achieve this, G1 CDKs, which are not able to promote replication initiation, inhibit pre-RC formation via at least two mechanisms: Cdc6 proteolysis and MCM2-7 nuclear export (Labib et al. 1999; Drury et al. 2000; Perkins et al. 2001). Other organisms presumably also insulate the initiation and licensing periods from one another, and some details of how this might occur are discussed below.

In summary, all known mechanisms in budding yeast that prevent rereplication are CDK-dependent, and these various mechanisms are thought to combine multiplicatively to create a virtually insurmountable barrier to rereplication (Fig. 3).

\section{Schizosaccharoymces pombe}

Like budding yeast, fission yeast replicates its genome from several hundred origins of replication spaced tens of kilobase pairs apart. S. pombe contains a single Cdk, called Cdc2. Cig1, Cig2, and Puc1 are S-phase cyclins, whereas Cdc13 is the mitotic cyclin. Rum1 inhibits the 
activity of Cdc2-Cdc13 (Correa-Bordes and Nurse 1995). As discussed above, the supreme role of CDKs in preventing rereplication was first discovered in fission yeast, where mutations in Cdc13, transient inhibition of Cdc2, or overexpression of Rum1 caused endocycles: multiple, discrete rounds of DNA replication with periodic origin licensing in the absence of mitosis. These observations suggest that in the absence of Cdc2-Cdc13, another Cdc2-dependent kinase stimulates DNA replication, and that this CDK undergoes periodic oscillations to allow repeated rounds of licensing and DNA replication. Cdc2-Cig2 is a good candidate because Cig2 overexpression in cells lacking Cdc13 prevents endoreduplication (Lopez Girona et al. 1998).

Early efforts to identify the targets of CDK inhibition focused on Cdc18, the fission yeast ortholog of Cdc6. As seen in budding yeast, Cdc18 is phosphorylated by Cdc2 in $\mathrm{S}$ phase, triggering ubiquitylation by the $\mathrm{SCF}^{\mathrm{Pop} 1}$ ligase and destruction by the proteasome (Jallepalli et al. 1997; Kominami and Toda 1997). Initially, it was thought that Cdc18 might be the only target of CDKdependent inhibition because high level Cdc18 overexpression, in particular alleles containing mutated CDK phosphorylation sites, causes rereplication (Nishitani and Nurse 1995; Jallepalli et al. 1997). However, a physiological level of nondegradable Cdc18 expression has no detectable effects on DNA replication in FACS assays, suggesting that other inhibitory mechanisms to prevent rereplication do exist (Nishitani and Nurse 1995; Muzi Falconi et al. 1996).

Like Cdc18, S. pombe Cdt1 is also regulated by proteolysis in the S and G2 phases (Nishitani et al. 2000; Gopalakrishnan et al. 2001). Cdt1 proteolysis requires a novel E3 ubiquitin ligase called Cul4-Ddb1 ${ }^{\mathrm{Cdt} 2}$ (Hu and Xiong 2006; Ralph et al. 2006). Interestingly, there is so far no evidence that this pathway is directly regulated by CDK, and experiments in other organisms show it is coupled to DNA replication (see below). Constitutive expression of Cdt1 alone is not sufficient to induce detectable rereplication, but when Cdt1 overexpression is combined with expression of nonphosphorylatable Cdc18, rereplication occurs, as seen by a gradual increase in ploidy (Nishitani et al. 2000; Gopalakrishnan et al. 2001; Yanow et al. 2001). Therefore, destruction of Cdt1 and Cdc18 represent overlapping mechanisms to prevent rereplication.

In addition to promoting Cdc18 destruction, $\mathrm{Cdc} 2-$ Cdc13 inhibits pre-RC assembly by binding to the fission yeast Orc2 (called Orp2), at origins of replication (Wuarin et al. 2002). This mechanism is thought to locally antagonize pre-RC assembly either via Cdc18 and/or Orp2 phosphorylation (Vas et al. 2001) or by creating a steric barrier to pre-RC assembly. In either case, localization of Cdc2-Cde13 to origins is specific to G2 and M phase, and origin localization of Cdc2 is not conferred by S-phase cyclins. Interestingly, ablation of Cdc2-Cdc13 binding to Orp2 does not cause rereplication, but endoreduplication (Wuarin et al. 2002). Thus, association of Cdc13Cdc2 with Orp2 is not essential to prevent origin refiring within S phase. Rather, this mechanism ensures that within G2 and M phase, further rounds of pre-RC assembly are blocked until the cell has entered anaphase.

In summary, $S$. pombe uses at least two strategies to prevent replication within S phase (Cdt1 and Cdc18 proteolysis), as well as a third mechanism to prevent relicensing in G2 and M (ORC inactivation by Cdc2-Cdc13) (Fig. 3). Since MCM2-7 is constitutively nuclear, $S$. pombe may not inhibit this pre-RC component.

\section{X. laevis}

The early embryonic cells cycles of the frog X. laevis take $\sim 30 \mathrm{~min}$ and consist of alternating $S$ and $M$ phases without intervening gap phases (for review, see Blow 2001). DNA replication initiates in a sequence-independent fashion at $\sim 300,000$ origins spaced $\sim 10 \mathrm{~kb}$ apart. Replication initiation is dependent on Cdk2-Cyclin E, mitotic entry is driven by Cdk1-Cyclin B, and mitotic exit is promoted by $\mathrm{APC}^{\mathrm{Cdc} 20}$. Two unique features of these cell cycles are noteworthy. First, these cells do not express APC ${ }^{\mathrm{Cdh} 1}$, explaining the absence of a G1 period (Lorca et al. 1998). Second, the activity of key cell cycle regulators fluctuates largely as a result of subcellular localization rather than expression level. Thus, Cdk2-Cyclin E levels are constant throughout the cell cycle (Hua et al. 1997). However, in mitosis, when there is no nuclear envelope, the Cdk2-Cyclin E concentration surrounding chromatin is low. Starting at telophase, Cdk2Cyclin $\mathrm{E}$ is imported into nuclei, causing a dramatic rise in its nuclear concentration that triggers initiation. Importantly, extracts prepared from unfertilized Xenopus eggs undergo precisely one round of DNA replication per in vitro cell cycle, making this a powerful tool to understand the regulation of DNA replication.

\section{Geminin}

Geminin was initially discovered in Xenopus egg extracts in a screen for $\mathrm{APC}^{\mathrm{Cdc} 20}$ substrates, and it was immediately recognized as an inhibitor of MCM2-7 loading (McGarry and Kirschner 1998). Present in all metazoans but apparently not in yeast, Geminin inhibits pre-RC assembly by sequestering Cdt1 in an inactive complex that is unable to interact with or recruit MCM2-7 (Wohlschlegel et al. 2000; Tada et al. 2001; Cook et al. 2004; Lee et al. 2004; Ferenbach et al. 2005; Lutzmann et al. 2006). Interestingly, Geminin does not inhibit the interaction of Cdt1 with origins of DNA replication (Gillespie et al. 2001). Crystal structures and mutational analyses reveal that Geminin assembles into a homodimer with a central coiled-coil domain that interacts extensively with Cdt1, and thereby probably creates a steric barrier that prevents association of Cdt 1 with MCM2-7 (Lee et al. 2004; Saxena et al. 2004).

In Xenopus egg extracts, Geminin is inactivated by $\mathrm{APC}^{\mathrm{Cdc} 20}$ at the metaphase-anaphase transition (McGarry and Kirschner 1998). Together with the destruction of mitotic cyclins, this event inaugurates the licensing period. Interestingly, only about half the endogenous 
Geminin is degraded in anaphase; the remainder is inactivated via an unknown mechanism that involves Geminin ubiquitylation (Li and Blow 2004). Geminin is reactivated when licensing ends in telophase, indicating that the licensing period during these cell cycles lasts only a few minutes. The mechanism of reactivation is not understood, but it is dependent on nuclear import of Geminin, after which the binding of Geminin to Cdt1 increases dramatically (Hodgson et al. 2002; Arias and Walter 2005; Lutzmann et al. 2006).

The properties of the Geminin that persists during the licensing period are controversial. The conventional view is that inactivated Geminin is unable to bind Cdt1 and therefore does not prevent licensing (Hodgson et al. 2002). However, a recent study suggests that Geminin and Cdt 1 form a complex that is competent for licensing (Lutzmann et al. 2006). In this view, Geminin only inhibits Cdt1 activity when a critical Geminin:Cdt1 ratio is achieved, which occurs after Geminin is reactivated in telophase. The fact that Xenopus Geminin is regulated post-translationally is probably crucial to allow it to switch rapidly between functional states, thereby accommodating the rapid embryonic cell cycles. It is unclear whether somatic cells contain similar populations of Geminin that are unable to inhibit the function of Cdt1.

The ability of Geminin to inhibit Cdt1 is apparently independent of CDK status (Ballabeni et al. 2004; Sugimoto et al. 2004; Li and Blow 2005). As such, the inhibition of Cdt1 by Geminin represents the first known CDK-independent means to prevent pre-RC assembly. Notably, immunodepletion of Geminin from Xenopus egg extracts was reported to induce no detectable rereplication (McGarry and Kirschner 1998), suggesting the existence of additional mechanisms to prevent rereplication (see next section).

\section{PCNA-dependent and Cul4-Ddb1 ${ }^{C d t 2}$-dependent Cdt1 proteolysis}

Cdt1 is destroyed in the $S$ phase of all metazoan cells (Nishitani et al. 2001; Zhong et al. 2003; Thomer et al. 2004; Arias and Walter 2005), and it has recently emerged that its proteolysis is intimately linked to DNA replication (Fig. 4A). Thus, in Xenopus egg extracts, it was first discovered that Cdt1 is ubiquitylated on chromatin in a manner that depends on the initiation of DNA replication (Arias and Walter 2005). Subsequent analysis showed that Cdt1 destruction depends on its binding to PCNA (Arias and Walter 2006). Xenopus Cdt1 contains a PCNA-interacting protein (PIP) box at its $\mathrm{N}$ terminus (shown as a red box in Fig. 4A). Mutation of the PIP box abolishes Cdt1 binding to PCNA, its ubiquitylation on chromatin, and its destruction in $S$ phase. Interestingly, PCNA-dependent Cdt1 ubiquitylation occurs exclusively on chromatin. Therefore, it appears that Cdt1 can only interact with chromatin-bound PCNA, a feature of the proteolysis mechanism that prevents Cdt1 destruction in G1 phase. Because it participates in the synthesis of every Okazaki fragment, PCNA accumu-

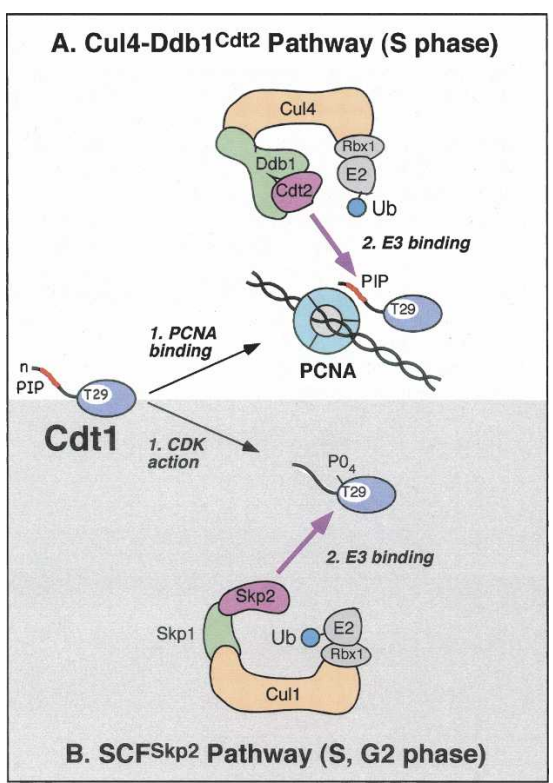

Figure 4. Cdt 1 proteolysis pathways. The two major pathways that target Cdt 1 for destruction are shown. The PIP box of Cdt 1 is indicated in red. (A) Cul4-Ddb1 ${ }^{\text {Cdt2 }}$-dependent Cdt1 destruction occurs in two steps. First, Cdt1 docks onto PCNA at DNA replication forks or sites of DNA damage. Second, Cdt2 interacts with the complex of Cdt1 and PCNA and ubiquitylates

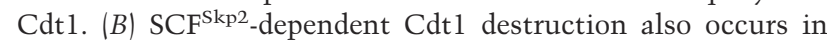
two steps. First, CDK phosphorylates Thr 29 (in humans). Second $\mathrm{SCF}^{\mathrm{Skp} 2}$ binds to the phoshporylated T29 via Skp2 and ubiquitin tranfer occurs.

lates to high levels on chromatin during $S$ phase (Arias and Walter 2006), making it a well-suited trigger for rapid Cdt 1 destruction. Importantly, all metazoan organisms contain a PIP box at the extreme $\mathrm{N}$ terminus of Cdt1 (Arias and Walter 2006; Senga et al. 2006), and current evidence indicates that PCNA-dependent Cdt1 destruction is highly conserved among these organisms (see below).

The E3 ubiquitin ligase that stimulates replicationdependent Cdt1 destruction in Xenopus egg extracts is a canonical cullin-based complex, Cul4-Ddb1 ${ }^{\text {Cdt2 }}$ (Fig. 4A; Arias and Walter 2006; Jin et al. 2006). Cul4 functions as a scaffold whose $\mathrm{N}$ terminus is bound by the adaptor Ddb1 and whose $\mathrm{C}$ terminus associates with an E2 ubiquitin-conjugating enzyme. The Ddb1 adaptor, in turn, interacts with the WD40 repeat protein, Cdt2, which probably binds directly to Cdt1. As expected from the ubiquitylation of Cdt1 on chromatin, Cul4-Ddb1 ${ }^{\mathrm{Cdt} 2}$ is also found on chromatin in S phase. Its binding to chromatin is dependent on initiation of DNA replication, and it requires the interaction of Cdt1 with PCNA. Thus, one model for PCNA-dependent Cdt1 destruction envisions that Cdtl docks onto PCNA via its PIP box, thereby creating a binding site for Cul4-Ddb1 ${ }^{\text {Cdt2 }}$ (Fig. 4A). It has also been reported that Cdt 1 is destroyed upon mitotic exit by the APC, but the function of this pathway in regulating replication is presently unclear ( $\mathrm{Li}$ and Blow 2005). 
What is the division of labor between Geminin and Cdt1 destruction in preventing rereplication? Blocking proteolysis of Cdt1 by itself yields no detectable rereplication (Arias and Walter 2005, 2006; Li and Blow 2005; Maiorano et al. 2005; Yoshida et al. 2005). Similarly, in the absence of Geminin, rereplication is not detectable (McGarry 2002; Arias and Walter 2005) or very inefficient (Li and Blow 2005; Yoshida et al. 2005; Kerns et al. 2006). However, when both mechanisms are neutralized, substantial rereplication occurs (Li and Blow 2005; Maiorano et al. 2005; Yoshida et al. 2005; Arias and Walter 2006). Therefore, it appears that Geminin and Cul4$\mathrm{Ddb} 1^{\mathrm{Cd} 2}$-dependent Cdt1 destruction are each sufficient to prevent the large majority of rereplication in interphase egg extracts.

\section{CDKs and rereplication in Xenopus}

Geminin and replication-dependent Cdt1 destruction both appear to be CDK-independent mechanisms to prevent rereplication, raising the question of whether CDK phosphorylation plays any role in blocking rereplication in Xenopus egg extracts. It was reported that recombinant human Cdk2-Cyclin E inhibits pre-RC formation when added at high concentrations to Xenopus egg extracts (Hua et al. 1997). However, simultaneous removal of Geminin and stabilization of Cdt1 induces rereplication in the presence of high nuclear concentrations of endogenous Cdk2-Cyclin E (see above), calling into question an inhibitory role for this kinase. The situation for Cdk1 is different. In metaphase-arrested Xenopus egg extracts, Cdk1 is nearly as potent as Geminin in preventing licensing (Tada et al. 2001). It appears to exert this effect by inhibiting the binding of the ORC complex to DNA (Mahbubani et al. 1997; Findeisen et al. 1999).

\section{Insulating the licensing and initiation periods in Xenopus egg extracts}

To prevent reinitiation during mitotic exit, cells must curtail initiation before enabling licensing. Importantly, new initiations cease well before mitotic exit, as soon as the nuclear envelope breaks down, because the concentration of replication factors such as Cdk2-Cyclin E around chromatin collapses (Arias and Walter 2004). Therefore, when the licensing period is subsequently inaugurated by $\mathrm{APC}^{\mathrm{Cdc} 20}$ in anaphase, there is no danger of reinitiation. Conversely, at the onset of DNA replication, which occurs after telophase, licensing must be terminated before initiation commences. We speculate that Geminin is imported and reactivated faster than Cdk2Cyclin E and other initiation factors. Importantly, the only other known inhibitory mechanism that operates in $S$ phase, Cdt1 destruction, commences only after replication has initiated, and therefore cannot contribute to insulation. The low amount of rereplication sometimes observed in the absence of Geminin (Li and Blow 2005; Yoshida et al. 2005; Kerns et al. 2006) may reflect a low level of reinitiation events that occur in early $S$ phase before all the Cdt1 has been destroyed.
In summary, early frog embryos use Geminin, Cdt1 destruction, and Cdk1 activity to prevent rereplication (Fig. 3). Unlike Geminin, which is active from the start of $\mathrm{S}$ phase until anaphase, Cdt1 destruction can only begin after replication forks have been established, and it may cease well before anaphase, if PCNA is unloaded rapidly upon completion of DNA replication. Finally, Cdk1-mediated inhibition is expected to commence sometime in G2, perhaps before Cdt1 destruction subsides. In this view, there is one window of time, very early in S phase, in which only one mechanism /Geminin) is known to operate. Perhaps additional, unknown mechanisms exist that help add an extra layer of control at this apparently vulnerable time in the Xenopus cell cycle.

\section{Mammals}

In mammalian cells, DNA replication initiates from some 25,000 origins spaced $\sim 100 \mathrm{~kb}$ apart. Replication initiation is promoted by Cdk2-Cyclin A, whereas mitosis depends on Cdk1-Cyclin A and Cdk1-Cyclin B. As seen in the early embryonic cell cycles of Xenopus, mammalian cells employ Geminin, Cul4-Ddb1 ${ }^{\text {Cdt2 }}$-dependent Cdt1 destruction, and Cdk1-mediated inhibition of ORC loading to prevent rereplication (Fig. 3). However, they also engage a second Cdt1 proteolysis pathway that requires $\mathrm{SCF}^{\mathrm{Skp} 2}$. In addition, several inhibitory mechanisms involving Cde6 and Orc1 have been postulated.

\section{Cdt1 destruction in $S$ phase}

Before the PCNA-dependent Cdt1 destruction pathway was discovered, there was evidence in mammalian cells that $\mathrm{Cdk} 2$ targets Cdt1 for destruction via the $\mathrm{SCF}^{\mathrm{Skp} 2}$ E3 ubiquitin ligase. Thus, Cdt1 was found to coimmunoprecipitate with Cdk2-Cyclin A, and phosphorylation of Cdt1 on Thr 29 was shown to be essential for its binding to the F-box protein, Skp2, which serves as the substrate receptor for $\mathrm{SCF}^{\text {Skp2 }}$ (see Fig. 4B; Li et al. 2003; Liu et al. 2004; Sugimoto et al. 2004; Takeda et al. 2005). At the time, it was surprising that mutations in human Cdt1 that abolish its interaction with Skp2 had little or no effect on Cdt1 stability in S phase (Takeda et al. 2005; Nishitani et al. 2006; Senga et al. 2006), and that $S k p 2^{-/-}$ mouse embryonic fibroblasts show no increase in Cdt1 levels (Nishitani et al. 2006). This paradox was resolved when it was shown that human Cdt 1 is also destroyed by the PCNA-dependent pathway (Nishitani et al. 2006; Senga et al. 2006). Thus, when the $\mathrm{SCF}^{\text {Skp2 }}$ pathway is neutralized, mutation of Cdt1's PIP box or siRNA against PCNA, Cul4, or Ddb1 all stabilize Cdt1 in S phase. In addition, indirect evidence now indicates that Cdt2 is also required for Cdt1 destruction in S phase (Jin et al. 2006; Sansam et al. 2006).

What is the relative importance of the $\mathrm{SCF}^{\mathrm{Skp} 2}$ and Cul4-Ddb1 ${ }^{\text {Cdt2 }}$ Cdt1 destruction pathways? In mammals, the two may overlap in S phase, since both path- 
ways must be neutralized to detect maximum Cdt1 accumulation (Nishitani et al. 2006; Senga et al. 2006). However, other results show that silencing of Cdt2 or Ddb1 is sufficient to induce Cdt1-dependent rereplication, whereas silencing of Skp2 has little or no effect (Jin et al. 2006; Lovejoy et al. 2006; Sansam et al. 2006), suggesting that the Cul4-Ddb1 ${ }^{\mathrm{Cdt} 2}$ pathway may predominate in S phase (see also below). In G2, the converse appears to be true: The $\mathrm{SCF}^{\text {Skp2 }}$ pathway remains active due to the continued presence of CDK activity, whereas the PCNA pathway subsides, presumably because PCNA has been unloaded from chromatin by this time (Nishitani et al. 2006). In other metazoans, the Cul4Ddb1 ${ }^{\text {Cdt2 }}$-dependent Cdt1 destruction pathway appears to predominate. Thus, mutation of the PIP box in Xenopus Cdt1, inhibition of DNA replication in flies, elimination of Cul4 in worms, and mutation of Cdt2 in zebrafish are all sufficient to stabilize Cdt1 and/or to induce rereplication (Zhong et al. 2003; Arias and Walter 2005, 2006; May et al. 2005; Sansam et al. 2006).

\section{Cdt1 destruction after DNA damage}

Experiments in human and Drosophila cells first showed that Cdt1 is destroyed not only in S phase, but also within minutes of exposure to DNA damage (Higa et al. 2003; Hu et al. 2004), a response that has been confirmed in fission yeast and frogs ( $\mathrm{Hu}$ and Xiong 2006; Jin et al. 2006; Ralph et al. 2006). Like S phase Cdt1 destruction, DNA damage-induced Cdt1 destruction requires Cul4, Ddb1, Cdt2, Cdt1's PIP box, and PCNA (Higa et al. 2003, 2006; Hu et al. 2004; Hu and Xiong 2006; Jin et al. 2006; Nishitani et al. 2006; Ralph et al. 2006; Sansam et al. 2006; Senga et al. 2006), but it does not require checkpoint kinases (Higa et al. 2003; Jin et al. 2006; Ralph et al. 2006). Therefore, the requirements for Cdt1 destruction in $\mathrm{S}$ phase and after DNA damage are indistinguishable, and both mechanisms likely involve docking of Cdt1 and the Cul4-Ddb1 ${ }^{\mathrm{Cdt} 2}$ ubiquitin ligase onto chromatinbound PCNA (Fig. 4A).

It has been proposed that destruction of Cdt1 is important to delay replication when DNA damage is incurred during G1 phase (Higa et al. 2003). However, considering that Cdt1 is dispensable for replication once MCM2-7 has been loaded (Maiorano et al. 2000, 2004), which normally occurs in telophase (Mendez and Stillman 2000; Okuno et al. 2001), this appears unlikely. As an alternative explanation, we propose that damage-induced destruction of Cdt1 may be important during G2 and $\mathrm{M}$ phase to prevent a spurious round of rereplication after checkpoint activation. DNA damage in G2 phase triggers checkpoint pathways that block entry into mitosis via inhibition of Cdk1 activity (Bartek et al. 2004). Because mitotic CDK activity is essential to prevent preRC assembly during $M$ phase (see below), down-regulation of Cdk1 by the DNA damage checkpoint could result in a new round of origin licensing. Upon checkpoint silencing, the reaccumulation of M-phase CDK activity would be predicted to trigger an additional round of origin firing (Bates et al. 1998; Prokhorova et al. 2003).
Thus, damage-induced destruction of Cdt1 may be critical to prevent a second round of replication indirectly brought on by checkpoint signaling.

It is interesting to revisit the mechanism of Cdt1 destruction in $S$. pombe. Because DNA damage in $S$. pombe also stimulates Cdt1 turnover, and this process requires PCNA, Ddb1, and Cdt2 (Hu and Xiong 2006; Ralph et al. 2006), it appears that Cdt1 docking onto chromatin-bound PCNA and subsequent ubiquitylation by Cul4-Ddb1 ${ }^{\mathrm{Cdt} 2}$ is conserved in this yeast. Although fission yeast Cdt1 does not contain a canonical PIP box [Q-X-x-(L/V/I/M)-x-x-(F/Y)-(F/Y)], its extreme $\mathrm{N}$ terminus contains a partial PIP box (Q-T-K-L), a motif recently shown to mediate binding of proteins to PCNA in budding yeast (Moldovan et al. 2006). A key question is now whether PCNA-dependent Cdt1 destruction contributes to the periodic expression of Cdt 1 in unperturbed fission yeast cell cycles. In support of this idea, Cdt1 levels normally drop after the G1/S transition (Nishitani et al. 2000; Gopalakrishnan et al. 2001), and mutations in $S$. pombe Ddb1 or Cdt2 lead to massive Cdt1 stabilization in unperturbed cells $\mathrm{Hu}$ and Xiong 2006; Ralph et al. 2006). So far, however, PCNA has not been implicated in Cdt1 turnover in unstressed cells (Hu and Xiong 2006), and this issue requires further investigation.

\section{Geminin}

Human Geminin is expressed during S, G2, and M phase, the periods of the cell cycle when licensing is prohibited (McGarry and Kirschner 1998; Wohlschlegel et al. 2000). In support of Geminin being an inhibitor of licensing in human cells, it binds to Cdt1 (Wohlschlegel et al. 2000), and its elimination in several cell lines causes substantial rereplication (Melixetian et al. 2004; Zhu et al. 2004). Geminin is a substrate of $\mathrm{APC}^{\mathrm{Cdc} 20}$ and $\mathrm{APC}^{\mathrm{Cdh} 1}$ (McGarry and Kirschner 1998; Rape et al. 2006). It is therefore destroyed together with mitotic cyclins in early anaphase, and it does not reaccumulate until late G1 when APC $^{\text {Cdh1 } 1}$ is inactivated. Ideally, Geminin levels should exceed Cdt1 levels in late G1, so that the licensing period terminates before replication initiates. This insulation may be achieved by $\mathrm{SCF}^{\mathrm{Skp} 2}$-dependent Cdt1 destruction.

Geminin can also play a positive role in origin licensing by preventing Cdtl proteolysis during mitosis (Ballabeni et al. 2004). Silencing of Geminin during G2/M phase causes a drastic decrease in Cdtl levels, resulting in reduced MCM2-7 chromatin loading in the following G1 phase. The binding of Geminin to Cdt1 probably protects the latter from destruction by the $\mathrm{SCF}^{\mathrm{Skp} 2}$ pathway in $M$ phase, which is consistent with the fact that in the presence of roscovotine, a Cdk1 inhibitor that should block the SCF pathway, Geminin depletion has little effect on Cdt1 stability. The destruction of Geminin in anaphase presumably liberates Cdt1, insuring that cells exit mitosis with a functional licensing apparatus (Fig. 5). This model does not, however, explain why Cdt1 is destroyed in $S$ phase despite the presence of Geminin 
(Nishitani et al. 2006; Senga et al. 2006). One possibility, illustrated in Figure 5, is that $\mathrm{SCF}^{\mathrm{Skp} 2}$ only targets free Cdt1, in contrast to Cul4-Ddb1 ${ }^{\mathrm{Cdt} 2}$, which eliminates free Cdt1 as well as the Geminin-bound form (Arias and Walter 2005). Thus, in S phase, Cdt1 is completely destroyed because all forms of Cdt1 are targeted. In G2, when the Cul4-Ddb1 ${ }^{\mathrm{Cdt} 2}$ pathway is switched off, Cdt1 bound to Geminin begins to accumulate, and this population peaks in mitosis, before its liberation from Geminin in anaphase. Protection of mammalian Cdt1 by Geminin is functionally analagous to $\mathrm{Clb} 2-\mathrm{Cdc} 28$ binding to Cdc6 in budding yeast (Mimura et al. 2004), in that both mechanisms repress pre-RC assembly in $M$ phase yet also ensure that pre-RC components are available at the start of the next cell cycle, when the inhibitor is destroyed by the APC.

\section{$C D K$}

While neutralization of Cdt1 is essential to prevent rereplication during $S$ phase, accumulating evidence indicates that the block to relicensing during G2 and M phase in mammals is critically dependent on Cdk 1 activity. First, conditional inactivation of Cdk1 in cycling cells is sufficient to induce endoreduplication (Itzhaki et al. 1997). Second, and similarly, transient overexpression of the CKI p21 during G2 phase induces a complete round of rereplication (Bates et al. 1998), reminiscent of genetic experiments in budding and fission yeast (Broek et al. 1991; Dahmann et al. 1995). Third, human and murine cells arrested in G2 or mitosis recruit ORC and MCM2-7 to chromatin if CDK activity is inhibited /Coverley et al. 1996, 1998; Fujita et al. 1998; Ballabeni et al. 2004; Li et al. 2004; Sugimoto et al. 2004). Strictly speaking, these experiments do not prove a direct role for CDK in preventing pre-RC formation, since in each experiment the cell cycle may have effectively been reset to a G1-like state. Another potential caveat is that the elimination of Cdk1 activity causes activation of $\mathrm{APC}^{\mathrm{Cdh} 1}$ and destruction of Geminin. However, in at least one study, chemical inactivation of Cdk1 induced pre-RC formation in mitosis in the continued presence of Geminin (Ballabeni et al. 2004). It has been proposed that in hamster cells, phosphorylation of Orc1 by Cdk1/Cyclin A prevents its association with chromatin ( $\mathrm{Li}$ et al. 2004). Moreover, mouse Cdt1 has DNA-binding activity that is blocked by CDK, but the physiological role of the
DNA binding and its regulation have not been established (Yanagi et al. 2002; Sugimoto et al. 2004). To test whether Cdk1 directly regulates these pre-RC components, it will be essential to eliminate their CDK phosphorylation sites and ask whether they can bind to chromatin in mitosis.

The role of Cdk2 in preventing rereplication in mammals is controversial. On the one hand, deregulation of Cdt1 during $S$ phase by different means is sufficient to induce rereplication (Vaziri et al. 2003; Melixetian et al. 2004; Zhu et al. 2004; Jin et al. 2006; Lovejoy et al. 2006; Sansam et al. 2006), and there is no reason to believe that Cdk2 activity was attenuated in these experiments, at least not initially, before rereplication induces DNA damage and checkpoint signaling (see below). Thus, any Cdk2-dependent inhibitory mechanisms, including $\mathrm{SCF}^{\text {Skp2 }}$-dependent Cdt1 destruction, are apparently not sufficient to prevent rereplication. On the contrary, expression of Cyclin A enhanced rereplication in mammalian tissue culture cells (Vaziri et al. 2003). The lack of an essential role for Cdk2 in regulating DNA replication is dramatically underscored by the observation that Cdk2 and Cyclin E knockout mice are viable (Berthet et al. 2003; Geng et al. 2003). On the other hand, a recent report suggests that $\mathrm{Cdk} 1$ and $\mathrm{Cdk} 2$ play redundant roles in preventing rereplication in Hela cells (Machida and Dutta 2007). As described above, Cdk2 is proposed to promote Cdt1 destruction via $\mathrm{SCF}^{\mathrm{Skp} 2}$, although there is so far no evidence that elimination of this pathway potentiates rereplication. Finally, expression of Cyclin E in human cells results in a shortened G1 phase and a decrease in MCM2-7 bound to chromatin (Ekholm-Reed et al. 2004). However, the mechanism underlying this overexpression phenotype remains unknown. In summary, more work is needed to determine what role, if any, $\mathrm{Cdk} 2$ kinase plays in regulating DNA replication during the mitotic cell cycle.

\section{Negative regulation of $O R C$ and Cdc6}

In mammals, considerable attention has focused on Orc1, the largest ORC subunit, as a target of negative regulation during the cell cycle (for review, see DePamphilis 2005). While there is good evidence that ORC is inhibited by Cdk1 activity in mitosis (Li et al. 2004), its fate during S and G2 is less clear. Some studies indicated that in S phase, Orc1 is partially destroyed via proteoly-

Figure 5. Model for cell cycle regulation of Cdt1 levels by Geminin and proteolysis. The left side of the figure shows that $\mathrm{SCF}^{\mathrm{Skp} 2}$ targets only free Cdt1, whereas Cul4-Ddb1 ${ }^{\text {Cdt2 }}$ can destroy free Cdt1 and Gemininbound Cdt1. The right side of the figure shows the abundance of Geminin and Cdt1 at different cell cycle stages. In cases where a factor is absent, it is replaced by an X. Thus, in S, G2, and M, there is no free Cdt1 due to the combined actions of SCF ${ }^{\text {Skp2 }}$ and Cul4-Ddb1 ${ }^{\mathrm{Cdt} 2}$. In

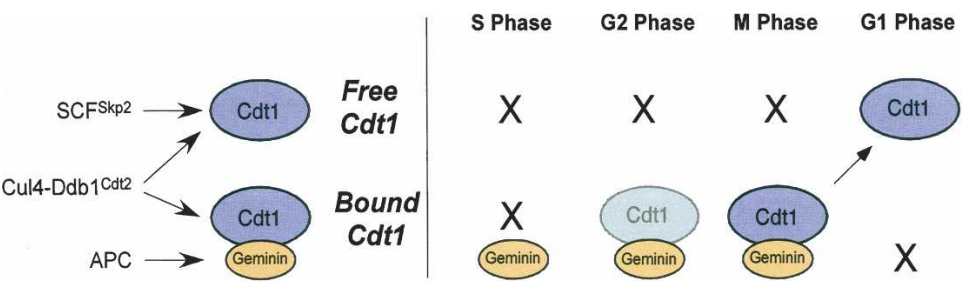
G2 and M phase, Cdt1 bound to Geminin accumulates because only Cul4-Ddb1 ${ }^{\text {Cdt2 }}$ can target this form of Cdt1, and this proteolysis pathway is turned off after S phase. Upon mitotic exit, APC destroys Geminin, thereby creating a free pool of Cdt1 in G1. 
sis (Mendez et al. 2002; Tatsumi et al. 2003), and that it is no longer detected at certain origins of replication (Ladenburger et al. 2002; Abdurashidova et al. 2003). Moreover, it has been reported that the interaction of Orc1 with chromatin is less tight in S and G2 than in G1 (Li and DePamphilis 2002). However, other studies conclude that the level of Orc1 and its interaction with chromatin do not fluctuate during this period (Saha et al. 1998; Okuno et al. 2001; McNairn and Gilbert 2005; McNairn et al. 2005). The reason for these differences is unclear. It is important to point out that mammalian cells, especially when transformed, contain a large functional excess of ORC (Dhar et al. 2001; McNairn and Gilbert 2005). Therefore, any mechanism of inhibition would have to eliminate the vast majority of cellular ORC to be effective. This is apparently not always the case, since mammalian G2 nuclei can replicate in ORCdepleted Xenopus egg extracts (Romanowski et al. 1996). A future challenge is to define and specifically disrupt mechanisms that regulate ORC function, and to determine whether cells are sensitized to rereplicate.

The role of mammalian Cdc6 in preventing rereplication is also uncertain. Initial studies in vertebrates showed that transfected Cdc6 is exported from nuclei under the control of CDK activity (Saha et al. 1998; Jiang et al. 1999; Petersen et al. 1999). However, subsequent work found that endogenous Cdc6 was bound to chromatin in S and G2 (Coverley et al. 2000; Mendez and Stillman 2000; Oehlmann et al. 2004), and that only the soluble pool of Cdc6 is exported (Alexandrow and Hamlin 2004). The observation that Cdc6 is chromatin-bound throughout $\mathrm{S}$ phase may also cast doubt on the functional relevance of ORC inactivation. Curiously, human Cdc6 is ubiquitylated by the APC during early G1 phase and gradually reaccumulates during S, G2, and M phases (Mendez and Stillman 2000; Petersen et al. 2000). It is unclear whether this destruction plays any role in preventing rereplication, as overexpression of nondegradable Cdc6 is not sufficient to induce rereplication (Petersen et al. 2000). Instead, APC-mediated destruction of Cdc6 may be important for maintaining low levels of Cdc6 during quiescence. Upon withdrawal from the cell cycle, mammalian cells arrest with an active APC that degrades Cdc6. When they are stimulated to re-enter the cell cycle, human Cdc6 reaccumulates despite APC activity because phosphorylation of Cdc6 by Cdk2/Cyclin E prevents its proteolysis (Mailand and Diffley 2005). Interestingly, no evidence for Cdk2/Cyclin E-dependent stabilization of Cdc6 has so far been observed in the mouse. When murine Cyclin E knockout cells are stimulated to re-enter the cell cycle from a quiescent state, Cdc6 levels accumulate with wild-type kinetics, despite the absence of protective Cyclin E phosphorylation (Geng et al. 2003). In summary, Cdc6 does not appear to be a major target of negative regulation during mitotic cell cycles, whereas it is down-regulated during quiescence.

There is currently no evidence to suggest that MCM2-7 is subject to direct negative regulation in mammals or any other metazoan. Unlike in budding yeast, MCM2-7 remains nuclear throughout S and G2 phases (Madine et al. 1995a,b; Todorov et al. 1995; Mendez and Stillman 2000). Given that Cdt1 deregulation is sufficient to promote rereplication in all metazoans examined, functional MCM2-7 complexes are probably present in the nucleus throughout the cell cycle.

\section{Interplay between mammalian inhibitors of pre-RC assembly}

As discussed above, Xenopus egg extracts contain several overlapping, if not redundant, mechanisms that prevent rereplication, and elimination of more than one mechanism is required to detect substantial rereplication. The situation in mammalian cells is less straightforward, since these cells contain the same mechanisms (and perhaps others), yet elimination of a single pathway is often sufficient to promote extensive rereplication.

In HeLa and MCF10A cells, Geminin siRNA does not induce detectable rereplication (Kulartz and Knippers 2004; Nishitani et al. 2004; Machida and Dutta 2007), demonstrating that Geminin is not essential to prevent the vast majority of rereplication in these cells. This implies that other mechanisms, such as Cdt1 proteolysis in $S$ phase (by SCF ${ }^{\text {Skp2 }}$ and Cul4-Ddb1 ${ }^{\text {Cdt2 }}$ ) and G2 (by $\mathrm{SCF}^{\mathrm{Skp} 2}$, and CDK-mediated inhibition of Cdt1 in mitosis, are highly active. Consistent with this idea, cosilencing of Geminin and Cyclin A leads to twice as much rereplication than when Cyclin A alone is inhibited, which also demonstrates that Geminin is active in these cells (Machida and Dutta 2007). A similar effect is achieved via silencing of Emi1, which leads to ectopic activation of $\mathrm{APC}^{\mathrm{Cdh} 1}$ and concomitant destruction of Geminin and Cyclin A (Machida and Dutta 2007). In contrast to the situation for Geminin, siRNA knockdown of Cdt2 or Ddb1 in HeLa cells is sufficient to cause significant rereplication, presumably due to relicensing in S phase (Jin et al. 2006; Lovejoy et al. 2006). In this situation, why are the $\mathrm{SCF}^{\text {Skp2 }}$ and Geminin pathways insufficient to prevent relicensing? One possibility is that the $\mathrm{SCF}^{\mathrm{Skp} 2}$ pathway is, in fact, not very active in these cells; as a result, Cdt1 accumulates in S phase and eventually exceeds Geminin, allowing relicensing. A related possibility is that local accumulation of small amounts of Cdt1 induces limited rereplication, triggering DNA damage, followed by down-regulation of Cdk2, inhibition of the SCF ${ }^{\text {Skp2 }}$ pathway, and further Cdt1 accumulation. In such an amplification loop, cells could eventually undergo massive rereplication. In summary, in Hela cells, Geminin is not essential to prevent detectable rereplication, in contrast to Cul4-Ddb $1^{\mathrm{Cdt} 2}$ and Cyclin A.

In other cell types (e.g., H1299 or HCT116 cancer cells), Geminin siRNA causes significant rereplication (Melixetian et al. 2004; Zhu et al. 2004). It may be that in these cells, the $\mathrm{SCF}^{\mathrm{Skp} 2}$ pathway is inactive. In this case, some origins might refire at the beginning of $S$ phase before Cdt 1 has been destroyed via the PCNA-dependent pathway. Another explanation is that in these cell types, one or more Cdt 1 proteolysis pathways could depend on 
Geminin. Although experiments in Xenopus egg extracts and HeLa cells argue against this notion (Nishitani et al. 2004; Arias and Walter 2005; Kerns et al. 2006), it is possible that cooperation between inhibitory pathways exists in some settings. Importantly, rereplication in the absence of Geminin also occurs in primary cells (Melixetian et al. 2004) and probably in mouse embryos (Gonzalez et al. 2006), indicating that this result is not an artifact of examining transformed cells.

\section{Caenorhabditis elegans}

In worms, the study of DNA replication is in its infancy, but this highly tractable system has already begun to make valuable contributions. For example, the observation that siRNA knockdown of Cul4 causes stabilization of Cdt1 and massive rereplication in the $S$ phase of a wide range of embryo blast cells, provided the first clue that a Cul4-based E3 ubiquitin ligase participates in the negative regulation of DNA replication (Zhong et al. 2003). Given that worms contain Cdt2 and that the PIP box of $\mathrm{CeCdt} 1$ is required for CeCdt1 destruction (Kim and Kipreos 2006), it appears that replication-dependent Cdt1 destruction is an essential defense against rereplication in these cells. Worms contain a putative geminin ortholog (GMN-1), but attempts to knock down its expression resulted in no clear DNA replication defects (Yanagi et al. 2005). The SCF ${ }^{\text {Skp2 }}$-dependent Cdt1 destruction pathway may not operate in worms, because skp2-mutant larvae are viable and exhibit no defects in Cdt1 destruction or DNA replication, nor does eliminating Skp2 enhance the replication defects seen when Cul4-Ddb1 function is compromised (Kim and Kipreos 2006). In summary, worms represent another example where experimental targeting of a single inhibitory pathway causes massive rereplication, and more work is needed to understand why this is the case.

\section{Flies}

Work in the flies Drosophila melanogaster and Sciara coprophila have illuminated the regulation of DNA replication during mitotic cell cycles and how this regulation is circumvented during endoreduplication and gene amplification. Flies are somewhat unique in that Cyclin $\mathrm{E}$ acts as the primary S-phase cyclin, both during mitotic and endocycles, whereas Cyclins A and B function as the mitotic cyclins (for review, see Lee and Orr-Weaver 2003). As seen in frogs and mammals, Cdt1 (called Double-parked, or Dup, in flies) is the major target of mechanisms that prevent rereplication. Thus, Drosophila Geminin binds Cdt1/Dup, and elimination of Geminin causes rereplication in Drosophila tissue culture cells and embryos (Quinn et al. 2001; Mihaylov et al. 2002; Higa et al. 2003). Cdt1/Dup is also degraded in the S phase of different cell types in Drosophila embryos (Whittaker et al. 2000; Thomer et al. 2004). Mutations in DNA replication proteins, including PCNA, stabilize Cdt1/Dup in S phase, as does removal of the Cdt1/Dup N terminus, which contains the PIP box motif, suggesting that the Cul4-Ddb1 ${ }^{\mathrm{Cdt} 2}$ pathway is active (Thomer et al. 2004; May et al. 2005). Cdt1/Dup destruction may also be controlled by CDK, since Cdt1/Dup is phosphorylated by CDK in vivo and because mutation of CDK consensus phosphorylation sites appears to enhance the rereplication activity of Cdt1/Dup under some conditions. Consistent with Cdt1/Dup proteolysis playing a role in regulating $\mathrm{S}$ phase, Cdt1 overexpression induces rereplication (Thomer et al. 2004). Drosophila Orc1 is also regulated by proteolysis, but it is ubiquitylated during the early G1 phase by APC ${ }^{\mathrm{Cdh} 1}$, a time when pre-RCs are normally formed, and the function of its destruction is not understood (Araki et al. 2003, 2005).

CDKs also play a critical role in regulating DNA replication in Drosophila. As seen in S. pombe, mutations in mitotic cyclins disrupt the dependency of successive $S$ phases on an intervening mitosis. Thus, disruption of Cyclin A in embryos or tissue culture cells induces a switch from a mitotic cell cycle to an endocycle (Sauer et al. 1995; Mihaylov et al. 2002). However, the targets of negative regulation by $\mathrm{Cdk} 1-\mathrm{Cyclin} \mathrm{A}$ are not known.

\section{Endocycles}

We now turn to endoreduplication, a special case of cell cycle-regulated DNA replication in which DNA synthesis is uncoupled from cell cycle progression. During metazoan development, certain cell types exit from the mitotic cell cycle and enter an endocycle, in which successive rounds of $S$ phase are separated by a Gap phase, in the absence of mitosis (Edgar and Orr-Weaver 2001). During Drosophila endocycles, Cdk2/Cyclin E activity oscillates between high levels in $\mathrm{S}$ phase and low levels in Gap phases (Lilly and Spradling 1996; MacAuley et al. 1998; Hattori et al. 2000). This cyclical expression is essential because continuous Cyclin E activity blocks endoreduplication (Calvi et al. 1998; Follette et al. 1998; Weiss et al. 1998). These results suggest that while $\mathrm{Cdk} 2 / \mathrm{Cyclin} \mathrm{E}$ is essential to promote origin firing in the endocycle, the cell must pass through a window of low Cdk2/Cyclin E activity, presumably to allow origin licensing. Endoreduplication therefore represents the clearest example in which Cdk2 can inhibit licensing.

The relevant target that is "reset" by low Cdk2 activity during the endocycle is unknown. However, it is not likely to be MCM2-7, because transient expression of Cyclin E in endocycling cells actually promotes rapid loading of MCM2-7 onto chromatin (Su and O'Farrell 1998). Thus, it appears that a low CDK environment is necessary for loading of an earlier licensing component (i.e., ORC, Cdc6, and/or Cdt1) and Cdt1 is a particularly attractive candidate. Both Cdt1 and Geminin are present in endocycling cells and during gene amplification cycles in developing nurse cells (Whittaker et al. 2000; Quinn et al. 2001). Moreover, Cdt1/Dup levels drop as endoreduplicating cells enter S phase, and Cdt1/Dup is rate-limiting during the amplification cycles (Thomer et al. 2004). Therefore, an attractive idea is that Cdk2-Cyclin E must be switched off in order to stop $\mathrm{SCF}^{\mathrm{Skp} 2}$-depen- 
dent Cdt1 turnover. Although regulation of Geminin activity within the endocycle has not been analyzed, APC activity is essential for the Drosophila endocycle to keep levels of mitotic cyclins low (Schaeffer et al. 2004). Thus, APC-mediated destruction of Geminin in the Gap phase could be important to allow temporal regulation of pre$\mathrm{RC}$ assembly.

During placental development, mammalian giant trophoblast cells enter into an endocycle and acquire DNA contents of up to 1000C (Zybina and Zybina 1996). The unique function of Cyclin $\mathrm{E}$ in the endocycle is highlighted by the fact that the only major defect observed in Cyclin E mutant mice is a lack of endoreduplication in trophoblast giant cells and megakaryocytes (Geng et al. 2003). As seen in flies, Cdk2-Cyclin E activity must oscillate during endoreduplication (MacAuley et al. 1998; Hattori et al. 2000). Another similarity is that Cdk2Cyclin E is required for MCM2-7 recruitment onto chromatin (Geng et al. 2003). Finally, recent evidence suggests that Geminin is down-regulated during mammalian endoreduplication (Gonzalez et al. 2006), and it will be interesting to understand how this and other mechanisms, such as Cdt1 destruction, contribute to the endocycle.

\section{Consequences of rereplication}

It is important to consider what happens when the mechanisms aimed at preventing rereplication fail. What is the nature of the DNA structures generated during rereplication and how do cells respond to these structures? When $S$. cerevisiae cells undergo rereplication, their chromosomes become fragmented (as seen by pulsed field gel electrophoresis), and they launch a rad9dependent, mrc1-independent checkpoint (Archambault et al. 2005; Green and Li 2005). Importantly, rad9 normally responds to DNA damage whereas Mrcl signals replication stress, indicating that chromsome breaks, and not stalled replication forks trigger the checkpoint. In mammalian cells that are rereplicating due to the absence of Geminin, Cdt2, or Ddb1, $\gamma$-H2AX staining and Comet assays indicate the presence of dsDNA breaks (Vaziri et al. 2003; Melixetian et al. 2004; Zhu et al. 2004; Jin et al. 2006; Lovejoy et al. 2006; Zhu and Dutta 2006). Single-stranded DNA is also detected, but it colocalizes with $\gamma-\mathrm{H} 2 \mathrm{AX}$ and therefore likely reflects resection of dsDNA ends. These cells launch a classical G2/M checkpoint: chk 1 and chk 2 are activated, and Cdk 1 activity is down-regulated, preventing entry into mitosis. Cdk2 is probably also inhibited because cells eventually cease rereplicating. Interestingly, inhibition of Chk1 in this setting drives cells into mitosis, causing mitotic catastrophe and apoptosis. Rereplication is also suppressed by Chk1 inhibition, probably because cells rapidly enter mitosis. Generally, similar results were obtained in Drosophila tissue culture cells (Mihaylov et al. 2002). In Xenopus egg extracts, addition of recombinant Cdt 1 after the first round of replication induces rereplication and Chk1 phosphorylation (Li and Blow 2005). Unlike what is seen in cells, inhibition of the checkpoint in egg ex- tracts enhances the amount of rereplication observed. Because the extracts used are not competent to enter mitosis, the only effect of blocking the checkpoint in this setting is to prevent the inhibition of Cdk2 activity that normally occurs during checkpoint activation (Costanzo et al. 2000, 2003). In summary, rereplication appears to give rise to dsDNA breaks, which in turn, triggers a DNA damage response, arresting cells in G2. The checkpoint effectively causes a permanent cell cycle arrest, and eventual apoptosis.

A critical question is whether checkpoint activation in rereplicating cells functions to rescue these cells from genomic instability, or, if rereplication is truly an irreparable genetic insult, whether checkpoint activation represents the first step in the initiation of programmed cell death. Interestingly, one report showed that a p53-dependent checkpoint reduces the amount of rereplication that is observed upon Cdtl overexpression (Vaziri et al. 2003). However, a substantial amount of DNA damage was likely required to trigger the checkpoint, and it remains uncertain whether this damage could be repaired. More work is clearly required to resolve these important questions.

How does rereplication generate DNA damage? When reinitiation is relatively infrequent, the resulting forks would travel a relatively large distance before encountering another fork (Fig. 6, left arrow, right side of chromosome). As a result, rereplication forks may stall and ultimately collapse, potentially generating DSBs or chicken foot structures. At higher initiation frequencies, the same locus may undergo multiple rapid initiation events, such that two replication forks travel in the same direction (Fig. 6, left arrow, left side of chromosome). If the second fork overtakes the first, both forks will likely collapse with generation of a dsDNA break (see expanded view). This phenomenon has recently been observed when rereplication in G2 phase is promoted in Xenopus egg extracts by overexpression of Cdt1 (Davidson et al. 2006). Other potential sources of DNA damage can be envisioned. Replicated sister chromatids are held together from $S$ phase until anaphase by the cohesin complex, which is thought to physically encircle the two sister chromatids in a proteinaceous ring (Losada and Hirano 2005). Thus, it is conceivable that rereplication imposes a physical stress on the cohesin ring, which could be signaled to checkpoint pathways. Alternatively, in G2 phase the histone pool may be insufficient to package the rereplicated DNA, leading to chromosome breakage.

A critical question, which has not been widely addressed, is what happens when only a very small number of reinitiation events take place (Fig. 6, right arrow). The resulting stalled forks may go undetected by the checkpoint machinery, and mitosis should proceed normally unless centromeric DNA is reduplicated. In the following $S$ phase, there are two possibilities. If replication initiation occurs on the rereplicated region (Fig. 6, right arrow, right chromosome arm), then the local increase in ploidy will be maintained after replication is complete. If, however, new initiation events do not occur on the 
Figure 6. Consequences of rereplication. (Top) After one normal round of DNA replication, different amounts of rereplication can occur. (Left arrow) During extensive rereplication, there is a significant probability that DNA replication will repeatedly initiate from the same site within a short time frame, which leads to the "bubble-within-a-bubble" structure shown on the left arm of the chromosome. If the younger DNA replication fork catches up with the older fork, double-stranded DNA breaks will arise, as shown in the expanded view. (Right arrow) When very low levels of rereplication take place, the rereplicated DNA can experience two fates as cells continue to cycle. First, as shown for the reinitiation bubble on the right arm, it will be propagated if, after mitosis and entry into the next $\mathrm{S}$ phase, DNA replication initiates on the rereplicated segment, and this will likely lead to recombination or chromosome fragmentation. Second, as shown for the reinitiation bubble on the left arm, it might be resolved in the subsequent $S$ phase if it does not support replication initiation.

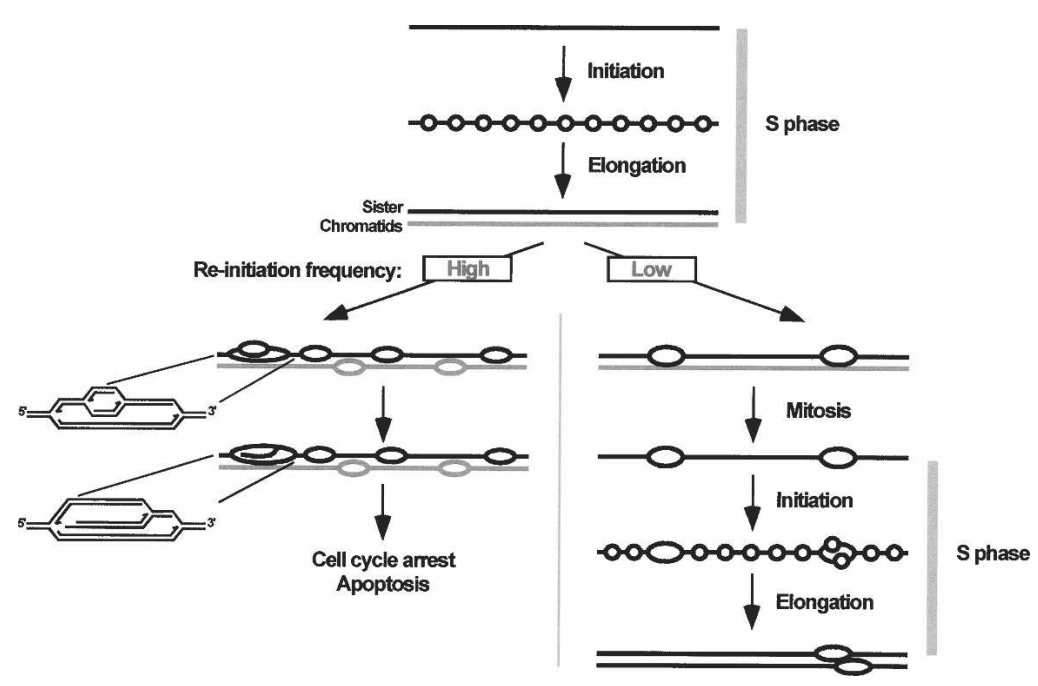

affected rereplicated segment, the problem might resolve itself (Fig. 6, right arrow, left chromosome arm). Therefore, it is tempting to speculate that cells have evolved a strategy to avoid replication initiation on regions that rereplicated in a pervious cell cycle, although it is not obvious how this might be accomplished. Because refiring of a small number of origins is likely to be the most common and most dangerous situation, it will be critical to understand the consequences of such subtle misregulation.

\section{Rereplication and disease}

It is striking that no mutations in the components of pre-RCs, or in the regulatory pathways that govern their assembly, have been identified in hereditary human diseases (DePamphilis 2006). However, as one might expect, there are some hints that deregulation of the licensing system can cause cancer. Thus, overexpression of Cdt1 confers on NIH3T3 cells the ability to form tumors in mice (Arentson et al. 2002), and overexpression of Cdt1 in thymocytes enhances tumor formation in the absence of p53 (Seo et al. 2005). Moreover, Cdt1 is overexpressed in several human cancers (Karakaidos et al. 2004; Xouri et al. 2004). How high-level Cdt1 expression arises, whether it plays a causal role in cancer, and how it might promote cancer remains to be determined. It has also been suggested that overexpression of Cyclin E may contribute to cancer by restricting origin licensing (Ekholm-Reed et al. 2004). However, this model awaits further confirmation of the role of this kinase in regulating pre-RC assembly. In general, major defects in the regulation of DNA replication are expected to cause cell death. Therefore, developing methods to detect very limited DNA rereplication in individual cells is of paramount importance. Such approaches will likely be essential to identify and characterize naturally occurring mu- tations in the licensing system and to understand their effects on genome stability and disease.

\section{Conclusions and outlook}

After an exciting decade of research, we now understand that eukaryotic cells regulate DNA replication via multiple mechanisms, all of which restrict access of the replicative DNA helicase to DNA from late G1 until the exit from mitosis. In budding yeast, a staggering array of overlapping pathways, all of them CDK dependent, conspire to block MCM2-7 chromatin binding. Some of these pathways, such as the proteolytic destruction of Cdc6 and the nuclear export of MCM2-7 are well understood, whereas others, such as the inhibition of ORC, remain obscure. Although the relative contributions of each pathway are uncertain, it is clear that several pathways are by themselves able to cause significant inhibition of rereplication, and that tight regulation results from the multiplicative effects of several mechanisms. An interesting question is what effect the ablation of individual inhibitory mechanisms has on rereplication.

With only one potential exception (worms), all metazoans utilize Geminin to prevent rereplication. Recently, PCNA-dependent Cdt1 destruction has emerged as a second, apparently universal mechanism to block licensing in $\mathrm{S}$ phase. The precise mechanism of how Cdt1 proteolysis is coupled to chromatin-bound PCNA, and whether this system is regulated by phosphorylation or other means, is an interesting topic for future study. Although the role of CDKs in preventing rereplication in metazoans is still unclear, and no pre-RC components have been clearly validated as targets, there is evidence that Cdk1 inhibits pre-RC formation late in the cell cycle. The role of Cdk2 in regulating rereplication during the mitotic cell cycle is even less certain, whereas it clearly blocks licensing during the endocycles. Ironi- 
cally, inducing rereplication by deregulating specific preRC components turned out to be much simpler in metazoans than in budding yeast. Thus, manipulations of single inhibitory mechanisms often cause massive rereplication. While this probably reflects the fact that multiple mechanisms target the same protein (Cdt1), we must consider the possibility that positive cross-talk between mechanisms causes catastrophic levels of rereplication when any one system is compromised. Why would evolution produce inhibitors of licensing that rely on each other for activity? Perhaps it is more advantageous to undergo massive rereplication, which induces cell death, than small amounts of rereplication, which could lead to heritable genomic instability. Even if they depend on each other, the existence of multiple pathways that inhibit pre-RC assembly is still advantageous, because under normal conditions, when all mechanisms are operational, they will cooperate to minimize relicensing. So far, there is no clear evidence of interdependent mechanisms, but testing this idea would require a thorough analysis of all known mechanisms under different conditions. A major challenge in the future is thus to carefully study the interplay of multiple inhibitory pathways in a single cell type.

\section{Acknowledgments}

We thank Joachim Li, Steve Bell, and Jonathan Millar for helpful discussions. E.E.A. was an HHMI predoctoral fellow. Our work on rereplication is supported by ACS grant 106201 to J.C.W.

\section{References}

Abdurashidova, G., Danailov, M.B., Ochem, A., Triolo, G., Dieliova, V., Radulescu, S., Vindigni, A., Riva, S., and Falaschi, A. 2003. Localization of proteins bound to a replication origin of human DNA along the cell cycle. EMBO T. 22: 42944303.

Alexandrow, M.G. and Hamlin, J.L. 2004. Cdc6 chromatin affinity is unaffected by serine- 54 phosphorylation, S-phase progression, and overexpression of cyclin A. Mol. Cell. Biol. 24: $1614-1627$.

Aparicio, O.M., Weinstein, D.M., and Bell, S.P. 1997. Components and dynamics of DNA replication complexes in $S$. cerevisiae: Redistribution of MCM proteins and Cdc45p during S phase. Cell 91: 59-69.

Araki, M., Wharton, R.P., Tang, Z., Yu, H., and Asano, M. 2003. Degradation of origin recognition complex large subunit by the anaphase-promoting complex in Drosophila. EMBO $\mathrm{J}$. 22: 6115-6126.

Araki, M., Yu, H., and Asano, M. 2005. A novel motif governs APC-dependent degradation of Drosophila ORC1 in vivo. Genes \& Dev. 19: 2458-2465.

Archambault, V., Ikui, A.E., Drapkin, B.J., and Cross, F.R. 2005. Disruption of mechanisms that prevent rereplication triggers a DNA damage response. Mol. Cell. Biol. 25: 6707-6721.

Arentson, E., Faloon, P., Seo, J., Moon, E., Studts, J.M., Fremont, D.H., and Choi, K. 2002. Oncogenic potential of the DNA replication licensing protein CDT1. Oncogene 21: 11501158.

Arias, E.E. and Walter, J.C. 2004. Initiation of DNA replication in Xenopus egg extracts. Front. Biosci. 9: 3029-3045.
Arias, E.E. and Walter, J.C. 2005. Replication-dependent destruction of Cdt1 limits DNA replication to a single round per cell cycle in Xenopus egg extracts. Genes \& Dev. 19: 114-126.

Arias, E.E. and Walter, J.C. 2006. PCNA functions as a molecular platform to trigger Cdt1 destruction and prevent re-replication. Nat. Cell Biol. 8: 84-90.

Ballabeni, A., Melixetian, M., Zamponi, R., Masiero, L., Marinoni, F., and Helin, K. 2004. Human Geminin promotes pre$\mathrm{RC}$ formation and DNA replication by stabilizing CDT1 in mitosis. EMBO J. 23: 3122-3132.

Bartek, J., Lukas, C., and Lukas, J. 2004. Checking on DNA damage in S phase. Nat. Rev. Mol. Cell Biol. 5: 792-804.

Bates, S., Ryan, K.M., Phillips, A.C., and Vousden, K.H. 1998. Cell cycle arrest and DNA endoreduplication following p21Waf1/Cip1 expression. Oncogene 17: 1691-1703.

Bell, S.P. and Dutta, A. 2002. DNA replication in eukaryotic cells. Annu. Rev. Biochem. 71: 333-374.

Berthet, C., Aleem, E., Coppola, V., Tessarollo, L., and Kaldis, P. 2003. Cdk2 knockout mice are viable. Curr. Biol. 13: 17751785.

Blow, J.J. 2001. New EMBO member's review: Control of chromosomal DNA replication in the early Xenopus embryo. EMBO I. 20: 3293-3297.

Blow, J.J. and Dutta, A. 2005. Preventing re-replication of chromosomal DNA. Nat. Rev. Mol. Cell Biol. 6: 476-486.

Blow, J.J. and Laskey, R.A. 1988. A role for the nuclear envelope in controlling DNA replication within the cell cycle. Nature 332: $546-548$.

Bowers, J.L., Randell, J.C., Chen, S., and Bell, S.P. 2004. ATP hydrolysis by ORC catalyzes reiterative $\mathrm{Mcm} 2-7$ assembly at a defined origin of replication. Mol. Cell 16: 967-978.

Brewer, B.J. and Fangman, W.L. 1993. Initiation at closely spaced replication origins in a yeast chromosome. Science 262: $1728-1731$.

Broek, D., Bartlett, R., Crawford, K., and Nurse, P. 1991. Involvement of p34cdc2 in establishing the dependency of S phase on mitosis. Nature 349: 388-393.

Calvi, B.R., Lilly, M.A., and Spradling, A.C. 1998. Cell cycle control of chorion gene amplification. Genes \& Dev. 12: 734-744.

Cook, J.G., Chasse, D.A., and Nevins, J.R. 2004. The regulated association of Cdt1 with minichromosome maintenance proteins and Cdc6 in mammalian cells. J. Biol. Chem. 279: 9625-9633.

Correa-Bordes, J. and Nurse, P. 1995. p25rum1 orders S phase and mitosis by acting as an inhibitor of the p34cdc2 mitotic kinase. Cell 83: 1001-1009.

Costanzo, V., Robertson, K., Ying, C.Y., Kim, E., Avvedimento, E., Gottesman, M., Grieco, D., and Gautier, J. 2000. Reconstitution of an ATM-dependent checkpoint that inhibits chromosomal DNA replication following DNA damage. Mol. Cell 6: 649-659.

Costanzo, V., Shechter, D., Lupardus, P.J., Cimprich, K.A., Gottesman, M., and Gautier, J. 2003. An ATR- and Cdc7dependent DNA damage checkpoint that inhibits initiation of DNA replication. Mol. Cell 11: 203-213.

Coverley, D., Wilkinson, H.R., and Downes, C.S. 1996. A protein kinase-dependent block to reinitiation of DNA replication in G2 phase in mammalian cells. Exp. Cell Res. 225: 294-300.

Coverley, D., Wilkinson, H.R., Madine, M.A., Mills, A.D., and Laskey, R.A. 1998. Protein kinase inhibition in G2 causes mammalian $\mathrm{Mcm}$ proteins to reassociate with chromatin and restores ability to replicate. Exp. Cell Res. 238: 63-69.

Coverley, D., Pelizon, C., Trewick, S., and Laskey, R.A. 2000. 
Chromatin-bound Cdc6 persists in S and G(2) phases in human cells, while soluble Cdc6 is destroyed in a cyclin A-cdk2 dependent process. J. Cell Sci. 113: 1929-1938.

Cvetic, C. and Walter, J.C. 2005. Eukaryotic origins of DNA replication: Could you please be more specific? Semin. Cell Dev. Biol. 16: 343-353.

Dahmann, C., Diffley, J.F., and Nasmyth, K.A. 1995. S-phasepromoting cyclin-dependent kinases prevent re-replication by inhibiting the transition of replication origins to a prereplicative state. Curr. Biol. 5: 1257-1269.

Davidson, I.F., Li, A., and Blow, J.J. 2006. Deregulated replication licensing causes DNA fragmentation consistent with head-to-tail fork collision. Mol. Cell 24: 433-443.

DePamphilis, M.L. 2005. Cell cycle dependent regulation of the origin recognition complex. Cell Cycle 4: 70-79.

DePamphilis, M.L. 2006. DNA replication and human disease. Cold Spring Harbor Laboratory Press, Cold Spring Harbor, NY.

Dhar, S.K., Yoshida, K., Machida, Y., Khaira, P., Chaudhuri, B., Wohlschlegel, J.A., Leffak, M., Yates, J., and Dutta, A. 2001. Replication from oriP of Epstein-Barr virus requires human ORC and is inhibited by geminin. Cell 106: 287-296.

Diffley, J.F. 1996. Once and only once upon a time: Specifying and regulating origins of DNA replication in eukaryotic cells. Genes \& Dev. 10: 2819-2830.

Diffley, J.F. 2004. Regulation of early events in chromosome replication. Curr. Biol. 14: R778-R786.

Diffley, J.F., Cocker, J.H., Dowell, S.J., and Rowley, A. 1994. Two steps in the assembly of complexes at yeast replication origins in vivo. Cell 78: 303-316.

Donaldson, A.D. 2000. The yeast mitotic cyclin Clb2 cannot substitute for $\mathrm{S}$ phase cyclins in replication origin firing. EMBO Rep. 1: 507-512.

Donovan, S., Harwood, J., Drury, L.S., and Diffley, J.F. 1997. Cdc6p-dependent loading of $\mathrm{Mcm}$ proteins onto pre-replicative chromatin in budding yeast. Proc. Natl. Acad. Sci. 94: 5611-5616.

Drury, L.S., Perkins, G., and Diffley, J.F. 1997. The Cdc4/34/53 pathway targets Cdc6p for proteolysis in budding yeast. EMBO T. 16: 5966-5976.

Drury, L.S., Perkins, G., and Diffley, J.F. 2000. The cyclin-dependent kinase Cdc28p regulates distinct modes of Cdc6p proteolysis during the budding yeast cell cycle. Curr. Biol. 10: $231-240$.

Duncker, B.P., Pasero, P., Braguglia, D., Heun, P., Weinreich, M., and Gasser, S.M. 1999. Cyclin B-cdk1 kinase stimulates ORC- and Cdc6-independent steps of semiconservative plasmid replication in yeast nuclear extracts. Mol. Cell. Biol. 19: 1226-1241.

Edgar, B.A. and Orr-Weaver, T.L. 2001. Endoreplication cell cycles: More for less. Cell 105: 297-306.

Edwards, M.C., Tutter, A.V., Cvetic, C., Gilbert, C.H., Prokhorova, T.A., and Walter, J.C. 2002. MCM2-7 complexes bind chromatin in a distributed pattern surrounding ORC in Xenopus egg extracts. J. Biol. Chem. 277: 33049-33057.

Ekholm-Reed, S., Mendez, J., Tedesco, D., Zetterberg, A., Stillman, B., and Reed, S.I. 2004. Deregulation of cyclin E in human cells interferes with prereplication complex assembly. J. Cell Biol. 165: 789-800.

Ferenbach, A., Li, A., Brito-Martins, M., and Blow, J.J. 2005. Functional domains of the Xenopus replication licensing factor Cdt1. Nucleic Acids Res. 33: 316-324.

Findeisen, M., El Denary, M., Kapitza, T., Graf, R., and Strausfeld, U. 1999. Cyclin A-dependent kinase activity affects chromatin binding of ORC, Cdc6, and MCM in egg extracts of Xenopus laevis. Eur. J. Biochem. 264: 415-426.
Follette, P.J., Duronio, R.J., and O'Farrell, P.H. 1998. Fluctuations in cyclin $\mathrm{E}$ levels are required for multiple rounds of endocycle S phase in Drosophila. Curr. Biol. 8: 235-238.

Fujita, M., Yamada, C., Tsurumi, T., Hanaoka, F., Matsuzawa, K., and Inagaki, M. 1998. Cell cycle- and chromatin binding state-dependent phosphorylation of human MCM heterohexameric complexes. A role for cdc2 kinase. J. Biol. Chem. 273: 17095-17101.

Gambus, A., Jones, R.C., Sanchez-Diaz, A., Kanemaki, M., van Deursen, F., Edmondson, R.D., and Labib, K. 2006. GINS maintains association of Cdc45 with MCM in replisome progression complexes at eukaryotic DNA replication forks. Nat. Cell Biol. 8: 358-366.

Geng, Y., Yu, Q., Sicinska, E., Das, M., Schneider, J.E., Bhattacharya, S., Rideout, W.M., Bronson, R.T., Gardner, H., and Sicinski, P. 2003. Cyclin E ablation in the mouse. Cell 114: 431-443.

Gillespie, P.J., Li, A., and Blow, J.J. 2001. Reconstitution of licensed replication origins on Xenopus sperm nuclei using purified proteins. BMC Biochem. 2: 15.

Gonzalez, M.A., Tachibana, K.E., Adams, D.J., van der Weyden, L., Hemberger, M., Coleman, N., Bradley, A., and Laskey, R.A. 2006. Geminin is essential to prevent endoreduplication and to form pluripotent cells during mammalian development. Genes \& Dev. 20: 1880-1884.

Gopalakrishnan, V., Simancek, P., Houchens, C., Snaith, H.A., Frattini, M.G., Sazer, S., and Kelly, T.J. 2001. Redundant control of rereplication in fission yeast. Proc. Natl. Acad. Sci. 98: 13114-13119.

Green, B.M. and Li, J.J. 2005. Loss of rereplication control in Saccharomyces cerevisiae results in extensive DNA damage. Mol. Biol. Cell 16: 421-432.

Green, B.M., Morreale, R.J., Ozaydin, B., Derisi, J.L., and Li, J.J. 2006. Genome-wide mapping of DNA synthesis in Saccharomyces cerevisiae reveals that mechanisms preventing reinitiation of DNA replication are not redundant. Mol. Biol. Cell 17: 2401-2414.

Harvey, K.J. and Newport, J. 2003. Metazoan origin selection: Origin recognition complex chromatin binding is regulated by CDC6 recruitment and ATP hydrolysis. J. Biol. Chem. 278: 48524-48528.

Hattori, N., Davies, T.C., Anson-Cartwright, L., and Cross, J.C. 2000. Periodic expression of the cyclin-dependent kinase inhibitor p57(Kip2) in trophoblast giant cells defines a G2-like gap phase of the endocycle. Mol. Biol. Cell 11: 1037-1045.

Hayles, J., Fisher, D., Woollard, A., and Nurse, P. 1994. Temporal order of $S$ phase and mitosis in fission yeast is determined by the state of the p34cdc2-mitotic B cyclin complex. Cell 78: 813-822.

Higa, L.A., Mihaylov, I.S., Banks, D.P., Zheng, J., and Zhang, H. 2003. Radiation-mediated proteolysis of CDT1 by CUL4ROC1 and CSN complexes constitutes a new checkpoint. Nat. Cell Biol. 5: 1008-1015.

Higa, L.A., Banks, D., Wu, M., Kobayashi, R., Sun, H., and Zhang, H. 2006. L2DTL/CDT2 interacts with the CUL4/ DDB1 complex and PCNA and regulates CDT1 proteolysis in response to DNA damage. Cell Cycle 5: 1675-1680.

Hodgson, B., Li, A., Tada, S., and Blow, J.J. 2002. Geminin becomes activated as an inhibitor of Cdt1/RLF-B following nuclear import. Curr. Biol. 12: 678-683.

$\mathrm{Hu}$, J. and Xiong, Y. 2006. An evolutionarily conserved function of proliferating cell nuclear antigen for cdt 1 degradation by the cul4-ddb1 ubiquitin ligase in response to DNA damage. J. Biol. Chem. 281: 3753-3756.

Hu, J., McCall, C.M., Ohta, T., and Xiong, Y. 2004. Targeted ubiquitination of CDT1 by the DDB1-CUL4A-ROC1 ligase 
in response to DNA damage. Nat. Cell Biol. 6: 1003-1009.

Hua, X.H. and Newport, J. 1998. Identification of a preinitiation step in DNA replication that is independent of origin recognition complex and cdc6, but dependent on cdk2. J. Cell Biol. 140: 271-281.

Hua, X.H., Yan, H., and Newport, J. 1997. A role for Cdk2 kinase in negatively regulating DNA replication during $S$ phase of the cell cycle. J. Cell Biol. 137: 183-192.

Hyrien, O., Marheineke, K., and Goldar, A. 2003. Paradoxes of eukaryotic DNA replication: MCM proteins and the random completion problem. Bioessays 25: 116-125.

Itzhaki, J.E., Gilbert, C.S., and Porter, A.C. 1997. Construction by gene targeting in human cells of a 'conditional' CDC2 mutant that rereplicates its DNA. Nat. Genet. 15: 258-265.

Jallepalli, P.V., Brown, G.W., Muzi-Falconi, M., Tien, D., and Kelly, T.J. 1997. Regulation of the replication initiator protein p65cdc18 by CDK phosphorylation. Genes \& Dev. 11: 2767-2779.

Jiang, W., Wells, N.J., and Hunter, T. 1999. Multistep regulation of DNA replication by Cdk phosphorylation of HsCdc6. Proc. Natl. Acad. Sci. 96: 6193-6198.

Jin, J., Arias, E.E., Chen, J., Harper, J.W., and Walter, J.C. 2006. A Family of diverse Cul4-Ddbl-interacting proteins includes $\mathrm{Cdt} 2$, which is required for $\mathrm{S}$ phase destruction of the replication factor Cdt1. Mol. Cell 23: 709-721.

Karakaidos, P., Taraviras, S., Vassiliou, L.V., Zacharatos, P., Kastrinakis, N.G., Kougiou, D., Kouloukoussa, M., Nishitani, H., Papavassiliou, A.G., Lygerou, Z., et al. 2004. Overexpression of the replication licensing regulators hCdt 1 and hCdc6 characterizes a subset of non-small-cell lung carcinomas: Synergistic effect with mutant p53 on tumor growth and chromosomal instability-Evidence of E2F-1 transcriptional control over hCdt1. Am. J. Pathol. 165: 1351-1365.

Kerns, S.L., Torke, S.J., Benjamin, J.M., and McGarry, T.J. 2006. Geminin prevents re-replication during Xenopus development. J. Biol. Chem. DOI: doi/10.1074/jbc.M609289200.

Kim, Y. and Kipreos, E.T. 2006. The C. elegans replication licensing factor CDT-1 is targeted for degradation by the CUL-4/DDB-1 complex. Mol. Cell Biol. DOI: 10.1128/ MCB.00736-06.

Kominami, K. and Toda, T. 1997. Fission yeast WD-repeat protein pop1 regulates genome ploidy through ubiquitin-proteasome-mediated degradation of the CDK inhibitor Rum 1 and the S-phase initiator Cdc18. Genes \& Dev. 11: 1548-1560.

Kubota, Y., Takase, Y., Komori, Y., Hashimoto, Y., Arata, T., Kamimura, Y., Araki, H., and Takisawa, H. 2003. A novel ring-like complex of Xenopus proteins essential for the initiation of DNA replication. Genes \& Dev. 17: 1141-1152.

Kulartz, M. and Knippers, R. 2004. The replicative regulator protein geminin on chromatin in the HeLa cell cycle. J. Biol. Chem. 279: 41686-41694.

Labib, K., Diffley, J.F., and Kearsey, S.E. 1999. G1-phase and B-type cyclins exclude the DNA-replication factor Mcm4 from the nucleus. Nat. Cell Biol. 1: 415-422.

Labib, K., Tercero, J.A., and Diffley, J.F. 2000. Uninterrupted MCM2-7 function required for DNA replication fork progression. Science 288: 1643-1647.

Ladenburger, E.M., Keller, C., and Knippers, R. 2002. Identification of a binding region for human origin recognition complex proteins 1 and 2 that coincides with an origin of DNA replication. Mol. Cell. Biol. 22: 1036-1048.

Lee, L.A. and Orr-Weaver, T.L. 2003. Regulation of cell cycles in Drosophila development: Intrinsic and extrinsic cues. Annu. Rev. Genet. 37: 545-578.

Lee, C., Hong, B., Choi, J.M., Kim, Y., Watanabe, S., Ishimi, Y., Enomoto, T., Tada, S., Kim, Y., and Cho, Y. 2004. Structural basis for inhibition of the replication licensing factor Cdt1 by geminin. Nature 430: 913-917.

Li, A. and Blow, J.J. 2004. Non-proteolytic inactivation of geminin requires CDK-dependent ubiquitination. Nat. Cell Biol. 6: $260-267$.

Li, A. and Blow, J.J. 2005. Cdt1 downregulation by proteolysis and geminin inhibition prevents DNA re-replication in Xenopus. EMBO J. 24: 395-404.

Li, C.J. and DePamphilis, M.L. 2002. Mammalian Orc1 protein is selectively released from chromatin and ubiquitinated during the S-to-M transition in the cell division cycle. Mol. Cell. Biol. 22: 105-116.

Li, X., Zhao, Q., Liao, R., Sun, P., and Wu, X. 2003. The SCF(Skp2) ubiquitin ligase complex interacts with the human replication licensing factor Cdt1 and regulates Cdt1 degradation. J. Biol. Chem. 278: 30854-30858.

Li, C.J., Vassilev, A., and DePamphilis, M.L. 2004. Role for Cdk1 (Cdc2)/cyclin A in preventing the mammalian origin recognition complex's largest subunit (Orc1) from binding to chromatin during mitosis. Mol. Cell. Biol. 24: 5875-5886.

Liku, M.E., Nguyen, V.Q., Rosales, A.W., Irie, K., and Li, J.J. 2005. CDK phosphorylation of a novel NLS-NES module distributed between two subunits of the Mcm2-7 complex prevents chromosomal rereplication. Mol. Biol. Cell 16: 5026-5039.

Lilly, M.A. and Spradling, A.C. 1996. The Drosophila endocycle is controlled by Cyclin E and lacks a checkpoint ensuring S-phase completion. Genes \& Dev. 10: 2514-2526.

Liu, E., Li, X., Yan, F., Zhao, Q., and Wu, X. 2004. Cyclindependent kinases phosphorylate human Cdt1 and induce its degradation. J. Biol. Chem. 279: 17283-17288.

Lopez Girona, A., Mondesert, O., Leatherwood, J., and Russell, P. 1998. Negative regulation of Cdc18 DNA replication protein by Cdc2. Mol. Biol. Cell 9: 63-73.

Lorca, T., Castro, A., Martinez, A.M., Vigneron, S., Morin, N., Sigrist, S., Lehner, C., Doree, M., and Labbe, J.C. 1998. Fizzy is required for activation of the APC/cyclosome in Xenopus egg extracts. EMBO J. 17: 3565-3575.

Losada, A. and Hirano, T. 2005. Dynamic molecular linkers of the genome: The first decade of SMC proteins. Genes \& Dev. 19: $1269-1287$.

Lovejoy, C.A., Lock, K., Yenamandra, A., and Cortez, D. 2006. DDB1 maintains genome integrity through regulation of Cdt1. Mol. Cell. Biol. 26: 7977-7990.

Lutzmann, M., Maiorano, D., and Mechali, M. 2006. A Cdt1geminin complex licenses chromatin for DNA replication and prevents rereplication during $\mathrm{S}$ phase in Xenopus. EMBO I. 25: 5764-5774.

MacAuley, A., Cross, J.C., and Werb, Z. 1998. Reprogramming the cell cycle for endoreduplication in rodent trophoblast cells. Mol. Biol. Cell 9: 795-807.

Machida, Y.J. and Dutta, A. 2007. The APC/C inhibitor, Emil, is essential for prevention of rereplication. Genes \& Dev. 21: 184-194.

Madine, M.A., Khoo, C.Y., Mills, A.D., and Laskey, R.A. 1995a. MCM3 complex required for cell cycle regulation of DNA replication in vertebrate cells. Nature 375: 421-424.

Madine, M.A., Khoo, C.Y., Mills, A.D., Mushal, C., and Laskey, R.A. 1995b. The nuclear envelope prevents reinitiation of replication by regulating the binding of MCM3 to chromatin in Xenopus egg extracts. Curr. Biol. 5: 1270-1279.

Maga, G. and Hubscher, U. 2003. Proliferating cell nuclear antigen (PCNA): A dancer with many partners. J. Cell Sci. 116: 3051-3060.

Mahbubani, H.M., Chong, J.P., Chevalier, S., Thommes, P., and Blow, J.J. 1997. Cell cycle regulation of the replication li- 
censing system: Involvement of a Cdk-dependent inhibitor. J. Cell Biol. 136: 125-135.

Mailand, N. and Diffley, J.F. 2005. CDKs promote DNA replication origin licensing in human cells by protecting Cdc6 from APC/C-dependent proteolysis. Cell 122: 915-926.

Maiorano, D., Moreau, J., and Mechali, M. 2000. XCDT1 is required for the assembly of pre-replicative complexes in Xenopus laevis. Nature 404: 622-625.

Maiorano, D., Rul, W., and Mechali, M. 2004. Cell cycle regulation of the licensing activity of Cdt1 in Xenopus laevis. Exp. Cell Res. 295: 138-149.

Maiorano, D., Krasinska, L., Lutzmann, M., and Mechali, M. 2005. Recombinant Cdt1 induces rereplication of G2 nuclei in Xenopus egg extracts. Curr. Biol. 15: 146-153.

Masai, H., Taniyama, C., Ogino, K., Matsui, E., Kakusho, N., Matsumoto, S., Kim, J.M., Ishii, A., Tanaka, T., Kobayashi, T., et al. 2006. Phosphorylation of MCM4 by CDC7 kinase facilitates its interaction with CDC45 on the chromatin. J. Biol. Chem. 281: 39249-39261.

Masuda, T., Mimura, S., and Takisawa, H. 2003. CDK- and Cdc45-dependent priming of the MCM complex on chromatin during S-phase in Xenopus egg extracts: Possible activation of MCM helicase by association with Cdc45. Genes Cells 8: 145-161.

Masumoto, H., Muramatsu, S., Kamimura, Y., and Araki, H. 2002. S-Cdk-dependent phosphorylation of Sld2 essential for chromosomal DNA replication in budding yeast. Nature 415: 651-655.

May, N.R., Thomer, M., Murnen, K.F., and Calvi, B.R. 2005. Levels of the origin-binding protein Double parked and its inhibitor Geminin increase in response to replication stress. J. Cell Sci. 118: 4207-4217.

McGarry, T.J. 2002. Geminin deficiency causes a Chk1-dependent G2 arrest in Xenopus. Mol. Biol. Cell 13: 3662-3671.

McGarry, T.J. and Kirschner, M.W. 1998. Geminin, an inhibitor of DNA replication, is degraded during mitosis. Cell 93: 1043-1053.

McNairn, A.J. and Gilbert, D.M. 2005. Overexpression of ORC subunits and increased ORC-chromatin association in transformed mammalian cells. J. Cell. Biochem. 96: 879-887.

McNairn, A.J., Okuno, Y., Misteli, T., and Gilbert, D.M. 2005 Chinese hamster ORC subunits dynamically associate with chromatin throughout the cell-cycle. Exp. Cell Res. 308: 345-356.

Melixetian, M., Ballabeni, A., Masiero, L., Gasparini, P., Zamponi, R., Bartek, J., Lukas, J., and Helin, K. 2004. Loss of Geminin induces rereplication in the presence of functional p53. J. Cell Biol. 165: 473-482.

Mendez, J. and Stillman, B. 2000. Chromatin association of human origin recognition complex, Cdc6, and minichromosome maintenance proteins during the cell cycle: Assembly of prereplication complexes in late mitosis. Mol. Cell. Biol. 20: 8602-8612.

Mendez, J. and Stillman, B. 2003. Perpetuating the double helix: Molecular machines at eukaryotic DNA replication origins. Bioessays 25: 1158-1167.

Mendez, J., Zou-Yang, X.H., Kim, S.Y., Hidaka, M., Tansey, W.P., and Stillman, B. 2002. Human origin recognition complex large subunit is degraded by ubiquitin-mediated proteolysis after initiation of DNA replication. Mol. Cell 9: 481491.

Mihaylov, I.S., Kondo, T., Jones, L., Ryzhikov, S., Tanaka, J., Zheng, J., Higa, L.A., Minamino, N., Cooley, L., and Zhang, H. 2002. Control of DNA replication and chromosome ploidy by geminin and cyclin A. Mol. Cell. Biol. 22: 18681880 .
Mimura, S., Seki, T., Tanaka, S., and Diffley, J.F. 2004. Phosphorylation-dependent binding of mitotic cyclins to Cdc6 contributes to DNA replication control. Nature 431: 11181123.

Moldovan, G.L., Pfander, B., and Jentsch, S. 2006. PCNA controls establishment of sister chromatid cohesion during S phase. Mol. Cell 23: 723-732.

Moll, T., Tebb, G., Surana, U., Robitsch, H., and Nasmyth, K. 1991. The role of phosphorylation and the CDC28 protein kinase in cell cycle-regulated nuclear import of the $S$. cerevisiae transcription factor SWI5. Cell 66: 743-758.

Morgan, D.O. 2007. The cell cycle. New Science Press Ltd, London.

Moyer, S.E., Lewis, P.W., and Botchan, M.R. 2006. Isolation of the Cdc45/Mcm2-7/GINS (CMG) complex, a candidate for the eukaryotic DNA replication fork helicase. Proc. Natl. Acad. Sci. 103: 10236-10241.

Muzi Falconi, M., Brown, G.W., and Kelly, T.J. 1996. cdc18 regulates initiation of DNA replication in Schizosaccharomyces pombe. Proc. Natl. Acad. Sci. 93: 1566-1570.

Nguyen, V.Q., Co, C., Irie, K., and Li, J.J. 2000. Clb/Cdc28 kinases promote nuclear export of the replication initiator proteins Mcm2-7. Curr. Biol. 10: 195-205.

Nguyen, V.Q., Co, C., and Li, J.J. 2001. Cyclin-dependent kinases prevent DNA re-replication through multiple mechanisms. Nature 411: 1068-1073.

Nishitani, H. and Nurse, P. 1995. p65cdc18 plays a major role controlling the initiation of DNA replication in fission yeast. Cell 83: 397-405.

Nishitani, H., Lygerou, Z., Nishimoto, T., and Nurse, P. 2000. The Cdt 1 protein is required to license DNA for replication in fission yeast. Nature 404: 625-628.

Nishitani, H., Taraviras, S., Lygerou, Z., and Nishimoto, T. 2001. The human licensing factor for DNA replication Cdt1 accumulates in G1 and is destabilized after initiation of Sphase. J. Biol. Chem. 276: 44905-44911.

Nishitani, H., Lygerou, Z., and Nishimoto, T. 2004. Proteolysis of DNA replication licensing factor Cdt1 in S-phase is performed independently of Geminin through its $\mathrm{N}$-terminal region. J. Biol. Chem. 279: 30807-30816.

Nishitani, H., Sugimoto, N., Roukos, V., Nakanishi, Y., Saijo, M., Obuse, C., Tsurimoto, T., Nakayama, K.I., Nakayama, K., Fujita, M., et al. 2006. Two E3 ubiquitin ligases, SCFSkp2 and DDB1-Cul4, target human Cdt1 for proteolysis. EMBO I. 25: 1126-1136.

Oehlmann, M., Score, A.J., and Blow, J.J. 2004. The role of Cdc6 in ensuring complete genome licensing and S phase checkpoint activation. J. Cell Biol. 165: 181-190.

Okuno, Y., McNairn, A.J., den Elzen, N., Pines, J., and Gilbert, D.M. 2001. Stability, chromatin association and functional activity of mammalian pre-replication complex proteins during the cell cycle. EMBO J. 20: 4263-4277.

Oshiro, G., Owens, J.C., Shellman, Y., Sclafani, R.A., and Li, J.J. 1999. Cell cycle control of Cdc7p kinase activity through regulation of Dbf4p stability. Mol. Cell. Biol. 19: 4888-4896.

Pacek, M. and Walter, J.C. 2004. A requirement for MCM7 and Cdc45 in chromosome unwinding during eukaryotic DNA replication. EMBO J. 23: 3667-3676.

Pacek, M., Tutter, A.V., Kubota, Y., Takisawa, H., and Walter, J.C. 2006. Localization of MCM2-7, Cdc45, and GINS to the site of DNA unwinding during eukaryotic DNA replication. Mol. Cell 21: 581-587.

Perkins, G. and Diffley, J.F. 1998. Nucleotide-dependent prereplicative complex assembly by Cdc6p, a homolog of eukaryotic and prokaryotic clamp-loaders. Mol. Cell 2: 23-32.

Perkins, G., Drury, L.S., and Diffley, J.F. 2001. Separate 
SCF(CDC4) recognition elements target Cdc6 for proteolysis in S phase and mitosis. EMBO J. 20: 4836-4845.

Petersen, B.O., Lukas, J., Sorensen, C.S., Bartek, J., and Helin, K. 1999. Phosphorylation of mammalian CDC6 by cyclin A/CDK2 regulates its subcellular localization. $E M B O ~ J .18$ : 396-410.

Petersen, B.O., Wagener, C., Marinoni, F., Kramer, E.R., Melixetian, M., Denchi, E.L., Gieffers, C., Matteucci, C., Peters, J.M., and Helin, K. 2000. Cell cycle- and cell growth-regulated proteolysis of mammalian CDC6 is dependent on APC-CDH1. Genes \& Dev. 14: 2330-2343.

Piatti, S., Bohm, T., Cocker, J.H., Diffley, J.F., and Nasmyth, K. 1996. Activation of S-phase-promoting CDKs in late G1 defines a 'point of no return' after which Cdc6 synthesis cannot promote DNA replication in yeast. Genes \& Dev. 10: 15161531.

Prokhorova, T.A., Mowrer, K., Gilbert, C.H., and Walter, J.C. 2003. DNA replication of mitotic chromatin in Xenopus egg extracts. Proc. Nat1. Acad. Sci. 100: 13241-13246.

Quinn, L.M., Herr, A., McGarry, T.J., and Richardson, H. 2001. The Drosophila Geminin homolog: Roles for Geminin in limiting DNA replication, in anaphase and in neurogenesis. Genes \& Dev. 15: 2741-2754.

Ralph, E., Boye, E., and Kearsey, S.E. 2006. DNA damage induces Cdt 1 proteolysis in fission yeast via a pathway dependent on Cdt2 and Ddb1. EMBO Rep. 7: 1134-1139.

Randell, J.C., Bowers, J.L., Rodriguez, H.K., and Bell, S.P. 2006. Sequential ATP hydrolysis by Cdc 6 and ORC directs loading of the Mcm2-7 helicase. Mol. Cell 21: 29-39.

Rao, P.N. and Johnson, R.T. 1970. Mammalian cell fusion: Studies on the regulation of DNA synthesis and mitosis. Nature 225: 159-164.

Rape, M., Reddy, S.K., and Kirschner, M.W. 2006. The processivity of multiubiquitination by the APC determines the order of substrate degradation. Cell 124: 89-103.

Romanowski, P., Madine, M.A., Rowles, A., Blow, J.J., and Laskey, R.A. 1996. The Xenopus origin recognition complex is essential for DNA replication and MCM binding to chromatin. Curr. Biol. 6: 1416-1425.

Rowles, A. and Blow, J.J. 1997. Chromatin proteins involved in the initiation of DNA replication. Curr. Opin. Genet. Dev. 7: 152-157.

Rowles, A., Tada, S., and Blow, J.J. 1999. Changes in association of the Xenopus origin recognition complex with chromatin on licensing of replication origins. J. Cell Sci. 112 (Pt 12): 2011-2018.

Saha, P., Chen, J., Thome, K.C., Lawlis, S.J., Hou, Z.H., Hendricks, M., Parvin, J.D., and Dutta, A. 1998. Human CDC6/ Cdc18 associates with Orc1 and cyclin-cdk and is selectively eliminated from the nucleus at the onset of $\mathrm{S}$ phase. Mol. Cell. Biol. 18: 2758-2767.

Sansam, C.L., Shepard, J.L., Lai, K., Ianari, A., Danielian, P.S., Amsterdam, A., Hopkins, N., and Lees, J.A. 2006. DTL/ CDT2 is essential for both CDT1 regulation and the early G2/M checkpoint. Genes \& Dev. 20: 3117-3129.

Santocanale, C., Sharma, K., and Diffley, J.F. 1999. Activation of dormant origins of DNA replication in budding yeast. Genes \& Dev. 13: 2360-2364.

Sauer, K., Knoblich, J.A., Richardson, H., and Lehner, C.F. 1995. Distinct modes of cyclin E/cdc2c kinase regulation and Sphase control in mitotic and endoreduplication cycles of Drosophila embryogenesis. Genes \& Dev. 9: 1327-1339.

Saxena, S., Yuan, P., Dhar, S.K., Senga, T., Takeda, D., Robinson, H., Kornbluth, S., Swaminathan, K., and Dutta, A. 2004. A dimerized coiled-coil domain and an adjoining part of geminin interact with two sites on Cdt1 for replication in- hibition. Mol. Cell 15: 245-258.

Schaeffer, V., Althauser, C., Shcherbata, H.R., Deng, W.M., and Ruohola-Baker, H. 2004. Notch-dependent Fizzy-related/ $\mathrm{Hec} 1 / \mathrm{Cdh} 1$ expression is required for the mitotic-to-endocycle transition in Drosophila follicle cells. Curr. Biol. 14: 630-636.

Senga, T., Sivaprasad, U., Zhu, W., Park, J.H., Arias, E.E., Walter, J.C., and Dutta, A. 2006. PCNA is a co-factor for Cdt1 degradation by CUL4/DDB1 mediated N-terminal ubiquitination. J. Biol. Chem. 281: 6246-6452.

Seo, J., Chung, Y.S., Sharma, G.G., Moon, E., Burack, W.R., Pandita, T.K., and Choi, K. 2005. Cdt1 transgenic mice develop lymphoblastic lymphoma in the absence of p53. Oncogene 24: 8176-8186.

Shechter, D., Ying, C.Y., and Gautier, J. 2004. DNA unwinding is an Mcm complex-dependent and ATP hydrolysis-dependent process. J. Biol. Chem. 279: 45586-45593.

Sheu, Y.J. and Stillman, B. 2006. Cdc7-Dbf4 phosphorylates MCM proteins via a docking site-mediated mechanism to promote S phase progression. Mol. Cell 24: 101-113.

Shimada, K., Pasero, P., and Gasser, S.M. 2002. ORC and the intra-S-phase checkpoint: A threshold regulates Rad53p activation in S phase. Genes \& Dev. 16: 3236-3252.

Shirayama, M., Toth, A., Galova, M., and Nasmyth, K. 1999. $\mathrm{APC}(\mathrm{Cdc} 20)$ promotes exit from mitosis by destroying the anaphase inhibitor Pds1 and cyclin Clb5. Nature 402: 203207.

Su, T.T. and O'Farrell, P.H. 1998. Chromosome association of minichromosome maintenance proteins in Drosophila endoreplication cycles. J. Cell Biol. 140: 451-460.

Sugimoto, N., Tatsumi, Y., Tsurumi, T., Matsukage, A., Kiyono, T., Nishitani, H., and Fujita, M. 2004. Cdt1 phosphorylation by cyclin A-dependent kinases negatively regulates its function without affecting geminin binding. J. Biol. Chem. 279: 19691-19697.

Tada, S., Li, A., Maiorano, D., Mechali, M., and Blow, J.J. 2001. Repression of origin assembly in metaphase depends on inhibition of RLF-B/Cdt1 by geminin. Nat. Cell Biol. 3: 107113.

Takahashi, T.S., Wigley, D.B., and Walter, J.C. 2005. Pumps, paradoxes and ploughshares: Mechanism of the MCM2-7 DNA helicase. Trends Biochem. Sci. 30: 437-444.

Takayama, Y., Kamimura, Y., Okawa, M., Muramatsu, S., Sugino, A., and Araki, H. 2003. GINS, a novel multiprotein complex required for chromosomal DNA replication in budding yeast. Genes \& Dev. 17: 1153-1165.

Takeda, D.Y. and Dutta, A. 2005. DNA replication and progression through S phase. Oncogene 24: 2827-2843.

Takeda, D.Y., Parvin, J.D., and Dutta, A. 2005. Degradation of Cdt1 during S phase is Skp2-independent and is required for efficient progression of mammalian cells through $\mathrm{S}$ phase. $J$. Biol. Chem. 280: 23416-23423.

Tanaka, S. and Diffley, J.F. 2002. Interdependent nuclear accumulation of budding yeast Cdt1 and $\mathrm{Mcm} 2-7$ during G1 phase. Nat. Cell Biol. 4: 198-207.

Tanaka, S., Umemori, T., Hirai, K., Muramatsu, S., Kamimura, Y., and Araki, H. 2007. CDK-dependent phosphorylation of Sld2 and Sld3 initiates DNA replication in budding yeast. Nature 445: 328-332.

Tanny, R.E., MacAlpine, D.M., Blitzblau, H.G., and Bell, S.P. 2006. Genome-wide analysis of re-replication reveals inhibitory controls that target multiple stages of replication initiation. Mol. Biol. Cell 17: 2415-2423.

Tatsumi, Y., Ohta, S., Kimura, H., Tsurimoto, T., and Obuse, C. 2003. The ORC1 cycle in human cells: I. Cell cycle-regulated oscillation of human ORC1. J. Biol. Chem. 278: 41528- 
41534.

Tercero, J.A., Labib, K., and Diffley, J.F. 2000. DNA synthesis at individual replication forks requires the essential initiation factor Cdc45p. EMBO J. 19: 2082-2093.

Thomer, M., May, N.R., Aggarwal, B.D., Kwok, G., and Calvi, B.R. 2004. Drosophila double-parked is sufficient to induce re-replication during development and is regulated by cyclin E/CDK2. Development 131: 4807-4818.

Todorov, I.T., Attaran, A., and Kearsey, S.E. 1995. BM28, a human member of the MCM2-3-5 family, is displaced from chromatin during DNA replication. J. Cell Biol. 129: 14331445.

Tsuji, T., Ficarro, S.B., and Jiang, W. 2006. Essential role of phosphorylation of MCM2 by Cdc7/Dbf4 in the initiation of DNA replication in mammalian cells. Mol. Biol. Cell 17: 4459-4472.

Vas, A., Mok, W., and Leatherwood, J. 2001. Control of DNA rereplication via $\mathrm{Cdc} 2$ phosphorylation sites in the origin recognition complex. Mol. Cell. Biol. 21: 5767-5777.

Vaziri, C., Saxena, S., Jeon, Y., Lee, C., Murata, K., Machida, Y., Wagle, N., Hwang, D.S., and Dutta, A. 2003. A p53-dependent checkpoint pathway prevents rereplication. Mol. Cell 11: 997-1008.

Walter, J.C. and Araki, H. 2006. Activation of pre-replication complexes. Cold Spring Harbor Laboratory Press, Cold Spring Harbor, NY.

Weinberg, D.H., Collins, K.L., Simancek, P., Russo, A., Wold, M.S., Virshup, D.M., and Kelly, T.J. 1990. Reconstitution of simian virus 40 DNA replication with purified proteins. Proc. Natl. Acad. Sci. 87: 8692-8696.

Weiss, A., Herzig, A., Jacobs, H., and Lehner, C.F. 1998. Continuous Cyclin E expression inhibits progression through endoreduplication cycles in Drosophila. Curr. Biol. 8: 239-242.

Whittaker, A.J., Royzman, I., and Orr-Weaver, T.L. 2000. Drosophila Double parked: A conserved, essential replication protein that colocalizes with the origin recognition complex and links DNA replication with mitosis and the down-regulation of S phase transcripts. Genes \& Dev. 14: 1765-1776.

Wilmes, G.M., Archambault, V., Austin, R.J., Jacobson, M.D., Bell, S.P., and Cross, F.R. 2004. Interaction of the S-phase cyclin Clb5 with an "RXL" docking sequence in the initiator protein Orc6 provides an origin-localized replication control switch. Genes \& Dev. 18: 981-991.

Wohlschlegel, J.A., Dwyer, B.T., Dhar, S.K., Cvetic, C., Walter, J.C., and Dutta, A. 2000. Inhibition of eukaryotic DNA replication by geminin binding to cdt1. Science 290: 2309-2312.

Woodward, A.M., Gohler, T., Luciani, M.G., Oehlmann, M., Ge, X., Gartner, A., Jackson, D.A., and Blow, J.J. 2006. Excess Mcm2-7 license dormant origins of replication that can be used under conditions of replicative stress. J. Cell Biol. 173: 673-683.

Wuarin, J., Buck, V., Nurse, P., and Millar, J.B. 2002. Stable association of mitotic cyclin $\mathrm{B} / \mathrm{Cdc} 2$ to replication origins prevents endoreduplication. Cell 111: 419-431.

Xouri, G., Lygerou, Z., Nishitani, H., Pachnis, V., Nurse, P., and Taraviras, S. 2004. Cdt1 and geminin are down-regulated upon cell cycle exit and are over-expressed in cancer-derived cell lines. Eur. J. Biochem. 271: 3368-3378.

Yanagi, K., Mizuno, T., You, Z., and Hanaoka, F. 2002. Mouse geminin inhibits not only Cdt1-MCM6 interactions but also a novel intrinsic Cdt1 DNA binding activity. J. Biol. Chem. 277: 40871-40880.

Yanagi, K., Mizuno, T., Tsuyama, T., Tada, S., Iida, Y., Sugimoto, A., Eki, T., Enomoto, T., and Hanaoka, F. 2005. Caenorhabditis elegans geminin homologue participates in cell cycle regulation and germ line development. J. Biol. Chem.
280: 19689-19694.

Yanow, S.K., Lygerou, Z., and Nurse, P. 2001. Expression of Cdc18/Cdc6 and Cdt1 during G2 phase induces initiation of DNA replication. EMBO J. 20: 4648-4656.

Ying, C.Y. and Gautier, J. 2005. The ATPase activity of MCM2-7 is dispensable for pre-RC assembly but is required for DNA unwinding. EMBO J. 24: 4334-4344.

Yoshida, K., Takisawa, H., and Kubota, Y. 2005. Intrinsic nuclear import activity of geminin is essential to prevent re-initiation of DNA replication in Xenopus eggs. Genes Cells 10: 63-73.

Zegerman, P. and Diffley, J.F. 2007. Phosphorylation of Sld2 and Sld3 by cyclin-dependent kinases promotes DNA replication in budding yeast. Nature 445: 281-285.

Zhong, W., Feng, H., Santiago, F.E., and Kipreos, E.T. 2003. CUL-4 ubiquitin ligase maintains genome stability by restraining DNA-replication licensing. Nature 423: 885-889.

Zhu, W. and Dutta, A. 2006. An ATR- and BRCA1-mediated fanconi anemia pathway is required for activating the G2/M checkpoint and DNA damage repair upon rereplication. Mol. Cell. Biol. 26: 4601-4611.

Zhu, W., Chen, Y., and Dutta, A. 2004. Rereplication by depletion of geminin is seen regardless of p53 status and activates a G2/M checkpoint. Mol. Cell. Biol. 24: 7140-7150.

Zybina, E.V. and Zybina, T.G. 1996. Polytene chromosomes in mammalian cells. Int. Rev. Cytol. 165: 53-119. 


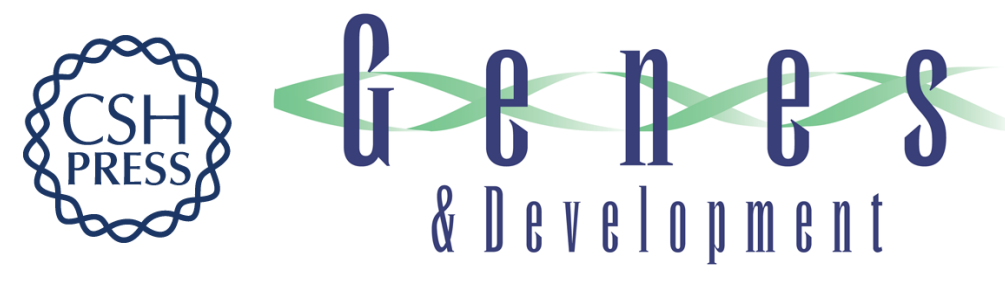

\title{
Strength in numbers: preventing rereplication via multiple mechanisms in eukaryotic cells
}

\author{
Emily E. Arias and Johannes C. Walter
}

Genes Dev. 2007, 21:

Access the most recent version at doi:10.1101/gad.1508907

$\begin{array}{ll}\text { References } & \text { This article cites } 193 \text { articles, } 97 \text { of which can be accessed free at: } \\ \text { http://genesdev.cshlp.org/content/21/5/497.full.html\#ref-list-1 }\end{array}$

License

Email Alerting Receive free email alerts when new articles cite this article - sign up in the box at the top Service right corner of the article or click here.

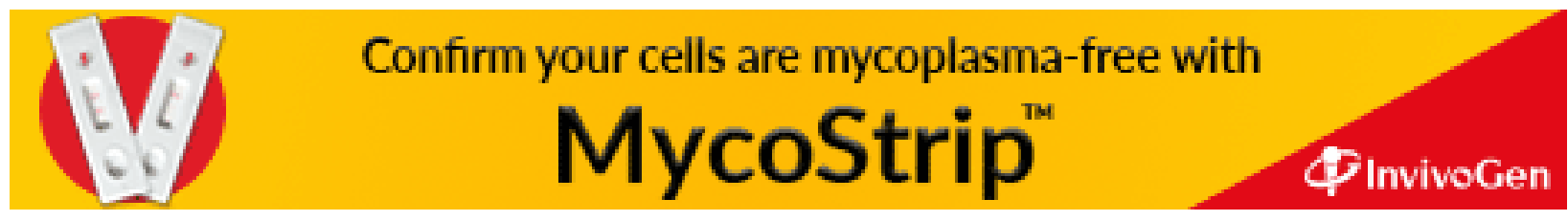

